Júlia Ferrúa dos Santos

\title{
Alterações no uso de hábitat por aves de subosque em paisagens fragmentadas
}

\author{
Change in habitat use by understory birds in \\ fragmented landscapes
}

São Paulo

2016 
Alterações no uso de hábitat por aves de subosque em paisagens fragmentadas

\section{Change in habitat use by understory birds in fragmented landscapes}

Dissertação apresentada ao Instituto de Biociências da Universidade de São Paulo, para a obtenção de Título de Mestre em Ciências, na Área de Ecologia.

Orientador(a): Cristina Camargo Banks Leite

São Paulo 


\section{Ficha Catalográfica}

Ferrúa dos Santos, Júlia

Alterações no uso do hábitat por aves de subosque em paisagens fragmentadas

$54 \mathrm{pp}$.

Dissertação (Mestrado) - Instituto de Biociências da Universidade de São Paulo. Departamento de Ecologia.

1. Uso do espaço 2. Aves de subosque 3. Taxa de recaptura. Universidade de São Paulo. Instituto de Biociências. Departamento de Ecologia.

Comissão Julgadora:

$\operatorname{Prof}(a)$. Dr(a).

$\operatorname{Prof}(a) . \operatorname{Dr}(a)$.

Prof(a). Dr.(a).

Orientador(a) 


\section{Agradecimentos}

Gostaria de agradecer à Cris Banks-Leite, pela orientação. Mesmo morando em outro país foi mais presente que muitos orientadores conseguem ser. Um agradecimento especial também à Renata Pardini e Kátia Ferraz que participaram do meu Comitê de Acompanhamento, e me ajudaram com críticas e sugestões durante o andamento do projeto.

Agradeço também ao Celso Parruco por toda ajuda (braçal, logística e psicológica) em campo. Também ao Lucas Giardulli por botar a mão na massa, carregando armadilhas nas costas. Ao Lucas Nascimento, pelo apoio emocional nos momentos difíceis e pela ajuda em campo também. No final os dados coletados não foram utilizados, mas as histórias e memórias do campo sempre fazem valer apena.

Um salve pra galera da Projete Liberdade Capoeira, que segurou minha onda em vários momentos. Os treinos, as rodas, as viagens, os rolês. Quantas vezes o axé da roda me resgatou de um dia ruim. Vocês são a minha família aqui em São Paulo e tenho certeza que minha experiência nessa cidade não teria sido tão incrível sem vocês.

Um agradecimento especial a minha mãe Alice e minha vó Ana Maria, que sempre me apoiaram nas minhas decisões, mesmo que estas tenham me levado pra longe. 


\section{Sumário}

$\begin{array}{ll}1-\text { Resumo } & 01\end{array}$

$\begin{array}{ll}2 \text { - Abstract } & 02\end{array}$

3 - Introdução 03

4 - Materiais e Métodos $\quad 07$

4.1. Área de Estudo 07

$\begin{array}{ll}\text { 4.2. Coleta de dados } & 10\end{array}$

4.3. Variáveis dependentes 11

4.4. Variáveis independentes 11

4.5. Grupos de espécies 12

4.6. Análises estatísticas $\quad 12$

5 - Resultados 13

5.1. Efeitos da perda de hábitat 13

5.2. Qualidade de hábitat $\quad 21$

6 - Discussão $\quad 24$

$\begin{array}{lr}7-\text { Conclusão } & 29\end{array}$

8 - Referências Bibliográficas $\quad 30$

9- Anexos 40 


\section{Resumo}

Os efeitos da perda de hábitat e da fragmentação já estão bem estabelecidos na literatura, porém pouco se sabe sobre como o uso do habitat pode ser modificado em função de alterações na quantidade e na qualidade da mata. Este trabalho tem como objetivo compreender melhor como a perda e modificação do hábitat afeta o uso do espaço pelas aves de subosque na escala da comunidade e população. Para isso, utilizamos um banco de dados de aves, que inclui informação sobre captura e recaptura de 2.121 indivíduos, coletados em um gradiente de cobertura florestal, com fragmentos de 2,85 ha a 10.000 ha, localizados em Mata Atlântica no estado de São Paulo. As análises foram feitas por espécie, por grupos de espécies de acordo com guilda trófica e grau de sensibilidade a alterações antrópicas, e para a comunidade de forma geral. Para testar se a qualidade da vegetação influencia a abundância e frequência de uso do espaço, utilizamos dados de três áreas de florestas contínuas, com diferentes níveis de alteração (floresta secundária, mata com corte seletivo e mata madura). Observamos que, apesar de haver uma queda na abundância total da comunidade em fragmentos pequenos, há um aumento na frequência de uso do ambiente, evidenciado pelo aumento na taxa de recaptura com a perda de habitat. $\mathrm{O}$ mesmo padrão foi encontrado para aves com média sensibilidade, frugívoras e insetívoras. Aves com baixa sensibilidade, no entanto, mostraram maiores abundancia e taxa de recaptura em fragmentos menores e áreas mais desmatadas. Verificamos também que a frequência de uso do espaço foi maior em floresta secundária, bem como a abundância de aves. Nossos resultados sugerem que além de conduzir a uma perda de espécies e de indivíduos, a perda de hábitat também leva ao aumento na intensidade do uso do habitat. Este aumento se dá em particular para espécies de média sensibilidade, uma vez que espécies com alta sensibilidade estão ausentes de fragmentos pequenos. Observamos que, além da matriz como barreira à dispersão, a própria qualidade da mata se apresenta como um fator que modifica o uso do habitat. Esta variação no uso do habitat pode impedir que as mesmas desenvolvam seu papel de dispersores de sementes entre os fragmentos. Por fim, estudos sobre uso do espaço hoje praticamente não abordam a intensidade com que o hábitat é utilizado pelos indivíduos, sendo uma informação importante que pode ser facilmente estudada através de dados de captura e recaptura, geralmente subutilizados. 


\section{Abstract}

The effects of habitat loss and fragmentation area well established in the literature, however not much is known about how habitat use can be modified due to alterations in habitat quantity and quality. This work aims to understand how habitat loss and changes to habitat quality affects the habitat use by understory birds at the community and population level. We analysed a database, which includes capture and recapture data from 2.121 individuals, of birds sampled along a gradient of Atlantic Forest cover and fragment size varying from 2,85 ha to 10.000 ha in the São Paulo State. We analysed data by species, by groups of species according to their trophic guilds and sensitivity to habitat change, and at the community level. To test if the quality of vegetation affects species abundance and the intensity of habitat use, we used data from three continuous forests, with different levels of habitat modification (secondary forest, forest selective logged and mature forest). Our results show that, although the total species abundance decreased in small fragments, the intensity of habitat use increases, as shown by the increase in recapture rates with habitat loss. This pattern was observed for birds with high and medium sensitivity, frugivorous and insectivorous. Species with low sensitivity, however, showed higher species abundance and recapture rate in small fragments. We also show that the frequency of habitat use was higher in secondary forest, as was the abundance of individuals. Our results suggest that habitat loss not only leads to smaller populations, but it also modifies the intensity of habitat use. This pattern was mostly observed for species with medium levels of sensitivity, as highly sensitive species were no longer present in small patches. Our results indicate that the matrix may act as a barrier for dispersal, but habitat quality may also further influence habitat use. This variation in habitat use can affect birds ability to disperse seeds between the fragments. Finally, studies of habitat use almost never focuses on the intensity of habitat use, even though this information can be easily evaluated using capture and recapture data, with the latter being usually underused. 


\section{Introdução}

A perda de hábitat é uma das principais causas da queda na biodiversidade, e diversos estudos mostram que a redução da quantidade de hábitat leva à extinção local das espécies (Lovejoy et al 1984; Saunders et al 1991; Bierregaard Jr et al 1992). As extinções locais geram alterações nas comunidades biológicas, modificando a composição e riqueza das mesmas (Boulinier et al 2001), podendo também afetar interações ecológicas - como polinização e parasitismo (Aizen \& Feinsinger 1994; Kruess \& Tscharntke 2000). Entretanto, há uma variação na resposta à perda de hábitat entre diferentes espécies (Martin \& Fahrig 2016), sendo que algumas espécies podem se beneficiar da redução da quantidade de mata (Dent \& Wright 2009). Essa variação na resposta dos animais reflete em padrões claros de substituição de espécies em áreas fragmentadas (Devictor et al 2008b).

Sabe-se que à medida que algumas espécies desaparecem dos fragmentos, outras se tornam abundantes (Saunders et al 1991; Banks-Leite et al 2012a). No entanto, pouco se sabe sobre os mecanismos pelos quais as espécies são extintas e os motivos que levam à tamanha variação na resposta das espécies à perda de habitat. Estudos apontam a capacidade de dispersão e características demográficas como possíveis moduladores da resposta das espécies (Henle et al 2004). Além disso, segundo Saunders et al (1991), as espécies mais susceptíveis à extinção seriam aquelas que ocorrem em baixas densidades, que precisam de grandes territórios e que possuem maior dependência da vegetação nativa. De forma geral, espera-se que a perda de habitat afete negativamente espécies especialistas de mata - incapazes de usar a matriz - e positivamente espécies mais generalistas que utilizam diversos tipos de hábitat (Debinski \& Holt 2000). Entretanto, a resposta à perda de mata depende do nível organizacional ecológico de interesse (e.g. comunidade, população, indivíduo).

No nível de população, o efeito de borda e a perda de conectividade levam à diminuição da taxa de crescimento populacional (Korfanta et al 2012) e, portanto, à queda na abundância (Lovejoy et al 1984; Stouffer \& Bierregaard 1995a; Stouffer \& Bierregaard 1995b). Também ocorre o isolamento entre populações (Fahrig 2003) e consequentemente 
a perda de variabilidade genética (Baur \& Erhardt 1995). Por outro lado, a densidade dos organismos pode ser positivamente afetada pela perda de hábitat, já que estudos mostram que em paisagens com maior perda de hábitat comumente há maior densidade de pequenos mamíferos, aves e insetos (Grez et al 2004; Matthysen 2005). Também há bastante divergência na literatura com relação à influência da qualidade do habitat na densidade dos organismos. Alguns estudos apontam áreas mais preservadas como locais com maior concentração de indivíduos (Schieck et al 1995; Maldonado-Coelho \& Marini 2000), enquanto outros registraram um maior número de organismos em áreas com níveis intermediários de preservação (Croxall 1976; Thiollay 1992, 1997).

As populações podem responder à modificação e perda de habitat por meio de variações no uso do espaço de cada indivíduo (Hinam \& St Clair 2008). Diversos estudos têm buscado entender como o uso do hábitat varia em função do ambiente e de características biológicas dos animais (Schoener \& Schoener 1982; Mysterud \& Ims 1998; Atwood \& Weeks Jr. 2003; Hinam \& St. Clair 2008). Sabe-se que a perda de hábitat reduz o tamanho da área de vida dos organismos e aumenta a sobreposição das mesmas por diferentes indivíduos (Ims et al 1993). Também, a perda de floresta altera a capacidade de dispersão dos organismos (Debinski \& Holt 2000), sendo que em alguns casos os animais podem se mover frequentemente entre várias manchas de habitat para suprir suas demandas por recursos (Andreassen et al 1998). Entretanto, na maioria dos casos, a movimentação entre os fragmentos se torna menos frequente (Diffendorfer et al 1995a; Baguette \& Van Dyck 2007), o que leva a um confinamento dos organismos dentro das machas de mata (Verboom et al 1991; Villard et al 1993). Essa série de observações divergentes aponta a necessidade de estudos mais profundos sobre a relação entre a perda de hábitat e a frequência de uso do espaço (Debinski \& Holt 2000).

A frequência de uso do espaço é um aspecto do uso do hábitat pouco explorado. São escassos os estudos que buscam compreender como a intensidade de uso do hábitat varia entre diferentes ambientes (Winker et al 1990; Trajano 1996; Lourenço 2011). Sabe-se, por exemplo, que espécies mais associadas a abrigos e com pequenas áreas de vida usam o ambiente mais intensamente (Lourenço 2011). Contudo, perturbações causadas à vegetação podem levar a diminuição da qualidade do habitat, o que força os indivíduos a aumentarem 
suas áreas de vida para obter os recursos necessários (Mitchell \& Powell 2004). Consequentemente, é esperado que a frequência do uso do espaço diminua em áreas perturbadas, desde que não haja descontinuidades no habitat (i.e. floresta contínua secundária). Por outro lado, o isolamento entre manchas florestais restringe a habilidade dos indivíduos de aumentarem suas áreas de vida, de forma que seria esperado um aumento da frequência de uso do espaço.

O método mais utilizado para estudar a frequência de uso de habitat é a rádio telemetria (Winker et al 1990; Castellón \& Sieving 2005; Sekercioglu et al 2007; Stouffer 2007). No entanto, este método requer um grande esforço de coleta, o que invariavelmente restringe o número de organismos que podem ser estudados, dificultando a obtenção de um banco de dados mais robusto. A alternativa mais comumente utilizada é o método de captura, marcação e recaptura que tem a vantagem de possibilitar o estudo de diferentes espécies da comunidade. Em especial, o padrão de recaptura de indivíduos pode descrever aspectos importantes do uso do espaço (Fleming et al 1972). Por exemplo, em um monitoramento de longo prazo, foi verificado que após o isolamento do fragmento a taxa de recaptura aumentou (Lovejoy et al 1984). Posteriormente, com o crescimento da floresta secundária no entorno do fragmento a taxa de recaptura começou a diminuir, já que a presença de uma matriz mais permeável facilitaria a dispersão dos animais para fora do remanescente florestal. Trajano (1996) relacionou em seu estudo altas taxas de recaptura de morcegos com o uso frequente de espaço, comportamento denominado pelo autor como sedentarismo. Lourenço (2011), igualmente, usou taxa de recaptura e número de indivíduos para medir a frequência de uso do ambiente, constatando que altas taxas de recaptura refletem no confinamento de morcegos em ilhas, quando comparado com dados do continente.

Aves de subosque, por sua vez, respondem fortemente à perda de mata (Lovejoy et al 1984; Bladón et al 2016), e este padrão é visto especialmente em espécies insetívoras (Banks-Leite et al 2013). As aves, no entanto, apresentam diversas dificuldades em estudos de telemetria por conta do tamanho reduzido e modo de locomoção aéreo da maioria das espécies. Aves de sub-bosque apresentam altas taxas de captura por redes de neblina, sendo que a taxa de recaptura desses animais juntamente com o número de indivíduos capturados 
consistem em boas ferramentas para estimar o uso do espaço (Lovejoy et al 1984). Entretanto, é necessário utilizar estas variáveis com cautela, uma vez que diversos fatores podem influenciá-las. Tanto o número de indivíduos capturados quanto a taxa de recaptura podem ser influenciadas por fatores metodológicos, climáticos e biológicos. As características das espécies como o uso vertical e horizontal do hábitat, densidade (Estades et al 2006), idade (Harris et al 1997; Drickamer et al 1999; Whitehead 2001), sexo (Drickamer et al 1999; Ogutu et al 2004), fidelidade espacial (Fearnbach et al 2012), tamanho (Jenni et al 1996), estágio reprodutivo (Jensen 1975, Prévot-Julliard 1998), frequência de vôo (MacArthur \& MacArthur 1974) e o ato de evitar a rede (Lovejoy et al 1984) podem alterar estas variáveis. Também, fatores metodológicos - local e tensão da rede (MacArthur \& MacArthur 1974) - e ambientais - clima (Tavecchia et al 2001), estrutura do hábitat (MacArthur \& MacArthur 1974), vento (Jenni et al 1996) e fragmentação (Lovejoy et al 1984) - podem afetar o número de indivíduos capturados e a taxa de recaptura.

Além disso, existem controvérsias sobre o quanto a própria captura de um indivíduo pode influenciar na recaptura do mesmo. MacArthur \& MacArthur (1974) acreditam que animais já capturados podem aprender a evitar as redes, alterando a probabilidade de recaptura, e que existe uma variação individual na capacidade de aprendizado de aves. Contudo, em estudos utilizando dados empíricos (Salewski et al 2007, Roche et al 2013) não se constatou evidência de que a captura altera a probabilidade de recaptura. Quanto à variação entre espécies, Jenni et al (1996) observaram que o ato de evitar a rede não variou entre indivíduos já capturados e indivíduos nunca capturados. O tempo de exposição ao método de captura pode alterar a capacidade de aprendizado dos animais, sendo assim em estudos com poucos dias de amostragem as aves não teriam tempo para aprender a evitar as redes.

Assim, este trabalho teve como principal objetivo compreender melhor como a perda de hábitat afeta o uso do espaço pelas aves de subosque. Dessa forma formulamos as seguintes perguntas e hipóteses: i) A abundância das espécies e intensidade de uso do habitat varia com a perda de mata? Esperamos encontrar uma correlação positiva entre abundância das espécies e quantidade de mata e uma maior intensidade de uso do hábitat (maior taxa de recaptura) em áreas com menor quantidade de mata; ii) A intensidade de uso 
do ambiente e a abundância variam com a qualidade da vegetação, quando não há perda de mata? Esperamos encontrar que em áreas mais alteradas as aves apresentem uma baixa frequência de uso do espaço e uma menor abundância. iii) Quais grupos de espécies são mais sensíveis à perda de hábitat? Espécies mais especialistas de hábitat e aves insetívoras responderão mais fortemente à perda de hábitat do que generalistas e frugívoros. .

\section{Métodos}

\section{1. Área de estudo}

Foram utilizados registros de aves previamente coletados pelo grupo BIOFRAG coordenado pelo Prof. Dr. Jean Paul Metzger. No presente estudo, utilizamos apenas as paisagens de Tapiraí, Parque Estadual de Jurupará (PEJ), Reserva Florestal do Morro Grande (RFMG) e Sakamoto (Fig. 1). Estas áreas estão localizadas no Planalto Atlântico do estado de São Paulo, onde a vegetação consiste em floresta ombrófila densa submontana. A altitude da região varia de 750 e $1000 \mathrm{~m}$ e as médias anuais de temperatura e precipitação são respectivamente $19^{\circ} \mathrm{C}$ e $1808 \mathrm{~mm}$ (http://www.cpa.unicamp.br). O período mais seco do ano compreende os meses entre abril e setembro, sendo também o mais frio. 


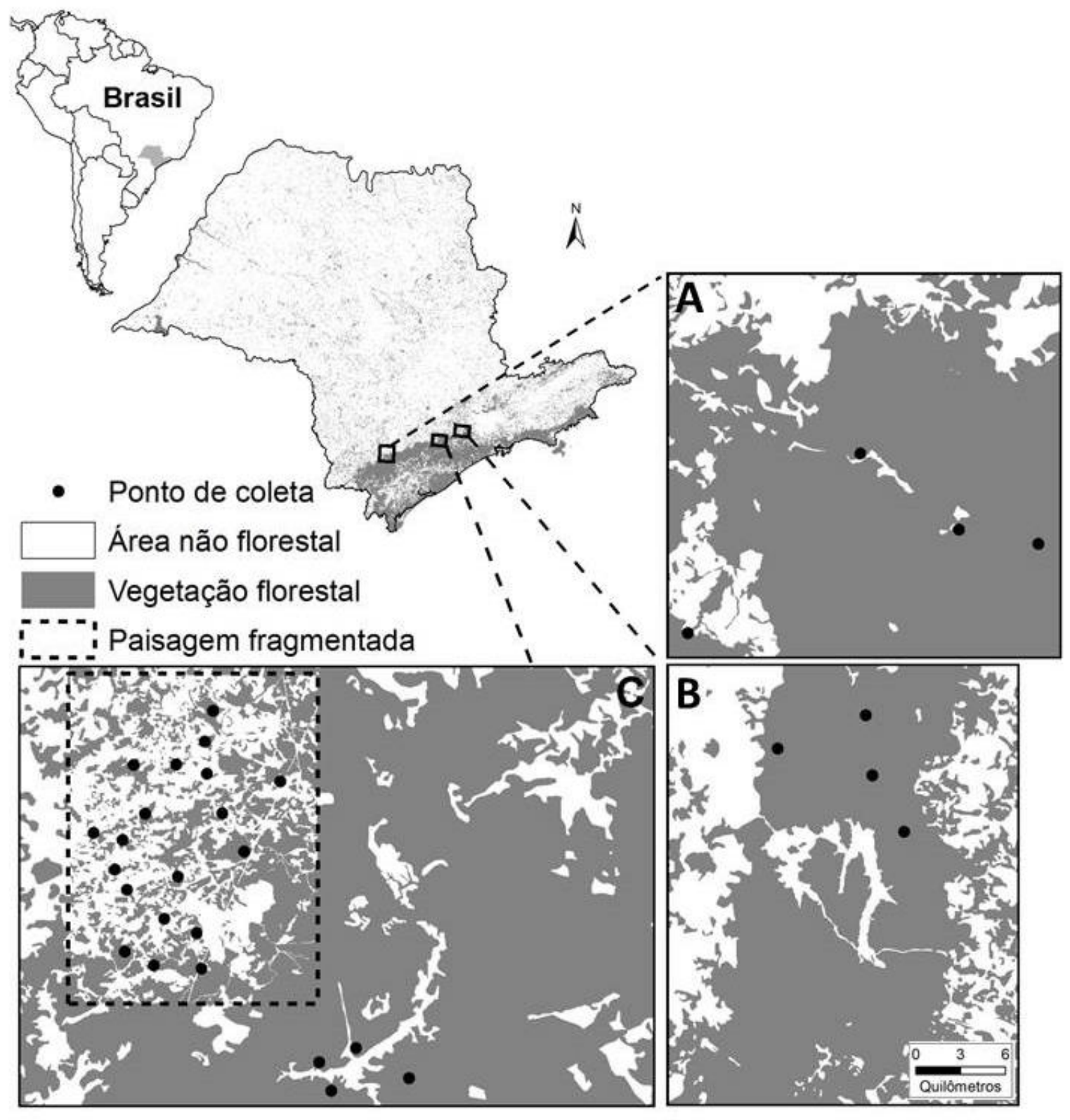

Figura 1. Mapa das áreas de estudo e sua localização no estado de São Paulo. No painel: A) Área de Sakamoto; B) Reserva Florestal do Morro Grande; C) Paisagem de Tapiraí dentro do retângulo pontilhado e Parque Estadual de Jurupará, adjacente.

\subsubsection{Tapiraí}

A paisagem de Tapiraí se localizada nas coordenadas $23^{\circ} 50^{\prime} \mathrm{S}, 4^{\circ} 20^{\prime} \mathrm{W}$ que possui cerca de 10.000 ha. Aproximadamente 50\% da paisagem consistem em florestas 
secundárias de 20 a 100 anos de regeneração, 38\% por terras agrícolas e o restante se baseava em plantações de eucaliptos, brejos e outros tipos de uso de terra. Nesta paisagem foram escolhidas 17 manchas de floresta em três categorias de tamanho (sete fragmentos entre 2 a 5 ha, oito fragmentos entre 18 a 41 ha e quatro fragmentos entre 78 e 156 ha), e dentro de cada categoria de tamanho, metade dos fragmentos possuíam altos níveis de conectividade e metade possuíam baixos níveis de conectividade (medidos pelo índice de proximidade calculado no Fragstats 3.3).

\subsubsection{Parque Estadual de Jurupará}

O Parque Estadual do Jurupará (PEJ) é uma área de floresta contínua localizada 23: $23^{\circ} 98^{\prime} \mathrm{S}, 47^{\circ} 50^{\prime} \mathrm{W}$, distante a $5 \mathrm{~km}$ da paisagem fragmentada, e tem por volta de 26.000 ha. No parque foram selecionados aleatoriamente quatro pontos amostrais, distantes pelo menos 1,5 km entre eles e $400 \mathrm{~m}$ da borda mais próxima. O PEJ sofreu corte seletivo apenas para extração palmito, consistindo hoje em uma floresta de estágio avançado de

regeneração, com a composição de espécies similar a de uma mata primária (Develey \& Metzger 2006).

\subsubsection{Reserva Florestal do Morro Grande}

A Reserva Florestal do Morro Grande (RFMG), que consiste em uma área de Floresta Ombrófila Densa Montana (Veloso et al 1991), com manchas de Floresta Estacional Semidecidual (Metzger et al 2006). A reserva possui uma área de cerca de 10.870 ha e se situa no município de Cotia (233' $\left.\mathrm{S}, 46^{\circ} 55^{\prime} \mathrm{W}\right)$. A RFMG sofreu corte raso há mais de 100 anos, consistindo atualmente em um mosaico de floresta secundária (sensu Brown \& Lugo 1990).

\subsubsection{Sakamoto}

A paisagem de Sakamoto é uma área de floresta contínua que possui 10.063 ha $\left(47^{\circ} 07^{\prime} \mathrm{SO}, 47^{\circ} 02^{\prime} \mathrm{NE}\right)$ que sofreu apenas corte seletivo. O clima da região é caracterizado como temperado quente e chuvoso por Köppen (1948), sendo que as médias mensais de temperatura e precipitação variam respectivamente de $17^{\circ} \mathrm{C}$ a $22^{\circ} \mathrm{C}$ e de 60 a $200 \mathrm{~mm}$ 
(Metzger et al 2006). A altitude varia entre 850 e $1100 \mathrm{~m}$ e a cobertura vegetal original é classificada como ombrófila densa montana (Veloso et al 1991).

\subsection{Coleta de dados}

Em Tapiraí e PEJ, cada ponto de coleta foi amostrado tanto na estação seca quanto na úmida ao longo de dois anos, assim fatores ambientais que poderiam enviesar os resultados foram controlados. Cada amostragem consistiu em dois dias consecutivos de captura, sendo utilizado o método de redes de neblina. No primeiro dia as redes ficaram abertas do nascer do sol ao pôr-do-sol, no segundo dia elas permaneceram abertas do nascer do sol até 6 horas depois. Como as replicas temporais de amostragem estavam separadas por vários meses, podemos assumir que as aves não aprendiam a posição das redes de neblina e por isso não as evitaram. Sendo assim, assumimos que não houve viés na taxa de recaptura. Em cada amostragem obtivemos um esforço de 170 redes/hora totalizando 680 redes/hora por ponto. No Sakamoto, o protocolo de amostragem foi essencialmente o mesmo, mas o numero total de horas-rede foi variável. Já na RFMG, o protocolo de amostragem foi diferente. As redes de neblina eram abertas no nascer do sol e fechadas oito horas depois. O mesmo local nunca foi amostrado por dois dias consecutivos, e cada local foi amostrado por até 8 dias ao longo de dois anos. Para mais detalhes ver Banks-Leite et al (2011).

Em todos os sítios amostrais, foram utilizadas 10 redes neblina de $12 \mathrm{~m}$ de comprimento, 2,5 m de altura e malha $31 \mathrm{~mm}$ para a captura das aves. As redes foram dispostas em linhas em trilhas previamente abertas. Todos os detalhes da coleta foram padronizados o máximo possível (e.g. posição da rede em relação à trilha, altura e tensão da rede) em todos os pontos para todas as campanhas. A cada hora as redes eram verificadas e o horário da captura de cada indivíduo foi marcado. Todas as aves capturadas receberam anilhas de alumínio numeradas provenientes do Centro de Pesquisa e Conservação de Aves Silvestres (CEMAVE - IBAMA), sendo posteriormente soltas. 


\subsection{Variáveis dependentes}

Para inferir abundância de indivíduos utilizamos o número de capturas de cada espécie em cada local, excluindo as recapturas. Dada a distância de nossos pontos amostrais, não foram registradas capturas de um mesmo indivíduo em locais diferentes. Para as análises de grupos de espécies e da comunidade, o número de indivíduos capturados foi somado para todas as espécies.

Para inferir a frequência de uso do espaço utilizamos o número de recapturas ponderado pelo numero de capturas. Esta taxa de recaptura nos possibilita analisar como a proporção de recapturas varia entre os diferentes sítios amostrais, ao mesmo tempo levando em consideração a variação no numero de indivíduos presentes no local. Desta forma, conseguimos diferenciar sítios amostrais que possuem mesma taxa de recaptura (e.g. 20\%), mas que tiveram numero totais de capturas bastante diferentes (e.g. 20 versus 100 indivíduos). Recapturas repetidas de um mesmo indivíduo foram contabilizadas. Como já visto anteriormente, muitos fatores podem influenciar o número de recapturas, e aqui assumimos que a variação da probabilidade de captura entre espécies diferentes, devido a suas particularidades biológicas, seria semelhante para todas as áreas amostrais.

\subsection{Variáveis independentes}

Para determinar a quantidade de hábitat presente nas manchas de mata amostradas utilizamos quatro métricas diferentes: Tamanho do fragmento medido em hectares e porcentagem de cobertura florestal medida em raios de $300 \mathrm{~m}, 500 \mathrm{~m}$ e $800 \mathrm{~m}$ do ponto central de amostragem. As métricas da paisagem foram obtidas através do software Fragstats 3.3 (McGarial \& Marks 1995), sendo utilizados mapas classificados em mata/nãomata, processados a partir de uma imagem Spot 5 com $10 \mathrm{~m}$ de resolução. Porém, como os resultados foram bastante semelhantes para tamanho de fragmento e porcentagem de cobertura florestal nos diferentes raios, apresentamos apenas os resultados para cobertura florestal medida no raio de $800 \mathrm{~m}$. 
Para testar como a abundância de indivíduos e frequência de uso do espaço variam com a qualidade da mata, comparamos estes registros entre as três paisagens de floresta contínua. Estas três áreas possuem históricos distintos de exploração da floresta e, portanto perfis diferentes de mata. O PEJ sofreu corte seletivo apenas para extração de palmito, consistindo hoje em uma floresta de estágio avançado de regeneração. A paisagem de Sakamoto sofreu apenas corte seletivo e a RFMG sofreu corte raso, consistindo atualmente em uma floresta secundária. Infelizmente, não há dados padronizados de estrutura florestal para todas as áreas.

\subsection{Grupos de espécies}

Para entender qual grupo de espécies é mais susceptível a alterações na abundância e na frequência de uso do espaço, escolhemos duas formas de agrupar as espécies: sensibilidade às alterações de hábitat e guilda trófica. Estas características foram escolhidas por serem indicadas como fatores importantes na resposta das espécies aos distúrbios (Ewers and Didham 2005). Para categorizar as espécies de acordo com níveis de sensibilidade às alterações de hábitat utilizamos informações disponibilizadas em Stotz et al (1996) e Develey (2004), sendo que as espécies foram divididas em nível alto, médio e baixo de sensibilidade, sendo relativo a espécies sensíveis, generalistas e especialistas em áreas alteradas, respectivamente. Para complementar esta informação, utilizamos também a quantidade de habitats que cada espécie pode ocorrer, definida por (Stotz et al 1996). Para as guildas tróficas (insetívoros, frugívoros e nectarívoros) utilizamos Hasui (2003), entretanto apenas espécies insetívoras e frugívoras foram utilizadas nessas análises, uma vez que os beija-flores, as principais aves nectarívoras, não foram anilhados o que impede o cálculo de recaptura.

\subsection{Análises estatísticas}

Para entender como a abundância varia em função da perda e da qualidade do hábitat, utilizamos GLM com erros de Poisson, dado que nossa variável dependente - 
número de indivíduos - segue esta distribuição. Para compreender a influência da quantidade de mata na taxa de recaptura das espécies utilizamos modelos lineares generalizados (GLM) com erros binomiais. Número de indivíduos e taxa de recaptura foram calculados para determinadas espécies, grupos (categorias de guilda trófica, níveis de sensibilidade e numero de habitats utilizados) e para a comunidade total. $\mathrm{O}$ uso de modelos lineares generalizados foi escolhido uma vez que nossas variáveis dependentes não seguem uma distribuição normal e não possuem variância constante.

\section{Resultados}

Foram utilizados dados de 103 espécies de aves, em um total de 2.657 capturas e 668 recapturas (Anexo I), sendo que o número de recaptura corresponde a 25,14\% do número de indivíduos e $20 \%$ de todas as capturas (capturas + recapturas).

\subsection{Efeitos da perda de hábitat}

\subsubsection{Análise da Comunidade}

O número total de indivíduos da comunidade aumentou com a cobertura florestal medida no raio de $800 \mathrm{~m}$ (Fig. 2a; p < 0,001, z =6,89), sendo observada resposta semelhante para todas as medidas de quantidade de hábitat (Anexo III). A taxa de recaptura também variou em relação à quantidade de mata. No entanto, observamos que - para a comunidade de aves - à medida que a quantidade de floresta aumenta, a taxa de recaptura diminui (Fig. 2b; $\mathrm{p}<0,001, \mathrm{z}=-5,07$ ). Pudemos constatar esse mesmo resultado para as quatro métricas utilizadas (Anexo IV). 
a)

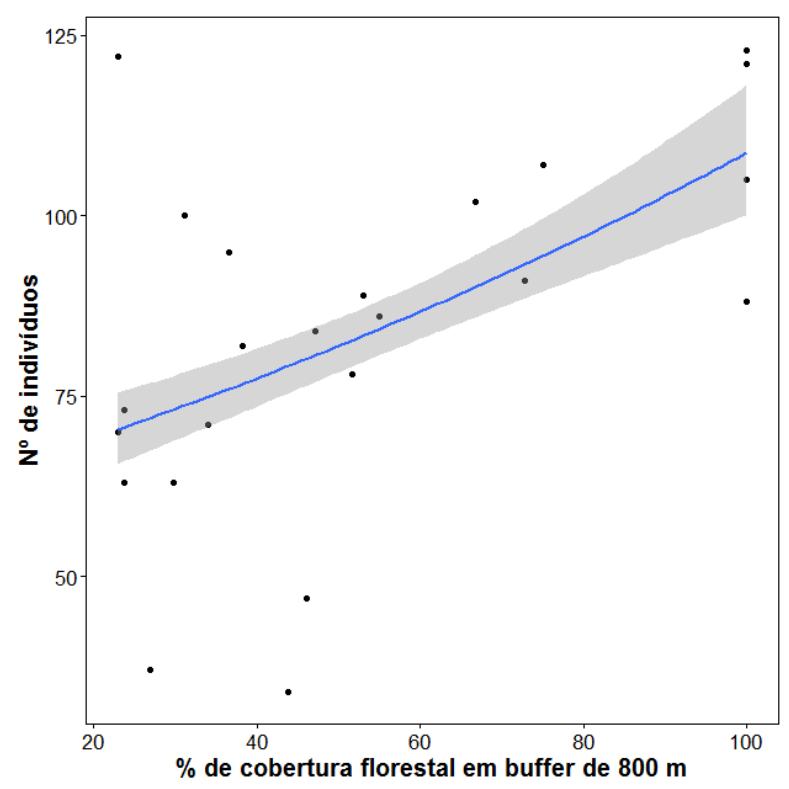

b)

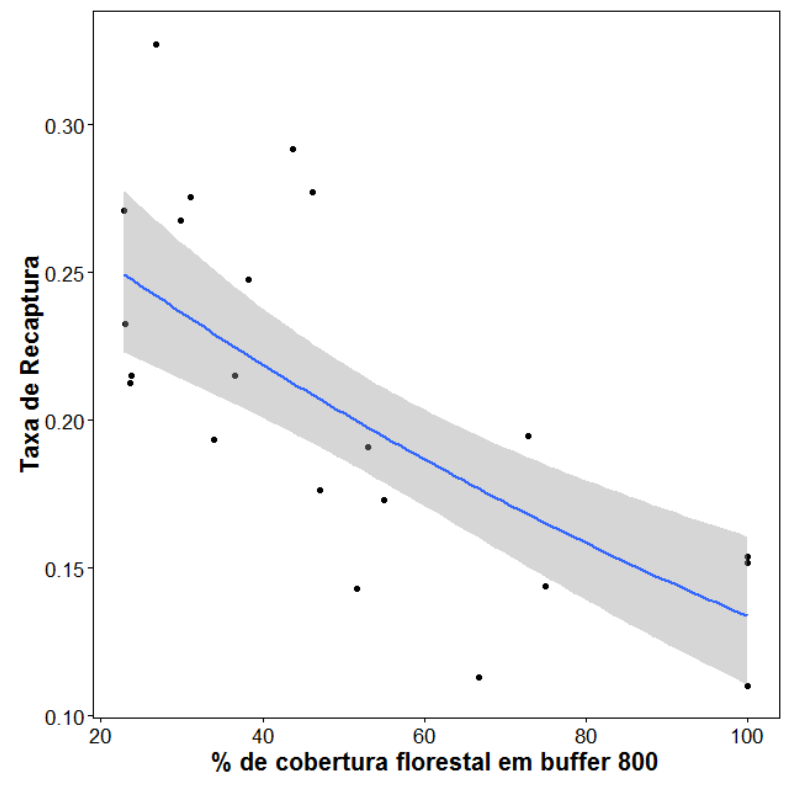

Figura 2. Relação entre a porcentagem de cobertura florestal medida em buffer de $800 \mathrm{~m}$ e a) o número total de indivíduos da comunidade de aves e b) a taxa de recaptura.

Constatamos que espécies com alta sensibilidade foram registradas principalmente em áreas com maior quantidade de mata (Anexo V), estando ausentes na maioria dos fragmentos pequenos e áreas desmatadas. Os resultados mostram também que o número de indivíduos capturados das espécies com baixa sensibilidade variam diferentemente em relação às outras duas categorias, sensíveis e generalistas (Fig. 3). Enquanto o número de indivíduos destas últimas aumenta com o aumento da quantidade de hábitat (alta sensibilidade: $\mathrm{p}<0,001, \mathrm{z}=5,53$ e sensibilidade média: $\mathrm{p}=0,005, \mathrm{z}=2,76$ ), a quantidade de indivíduos das espécies com baixa sensibilidade diminui com o aumento da quantidade de mata $(p<0,001, z=-9,25)$. Apesar da resposta das espécies generalistas ser igual à de espécies sensíveis, a intensidade da resposta foi maior para sensíveis. O mesmo padrão foi encontrado para tamanho de fragmento e porcentagem de cobertura florestal em buffers de 300 e 500 m (Anexos VI, VII e VIII). 

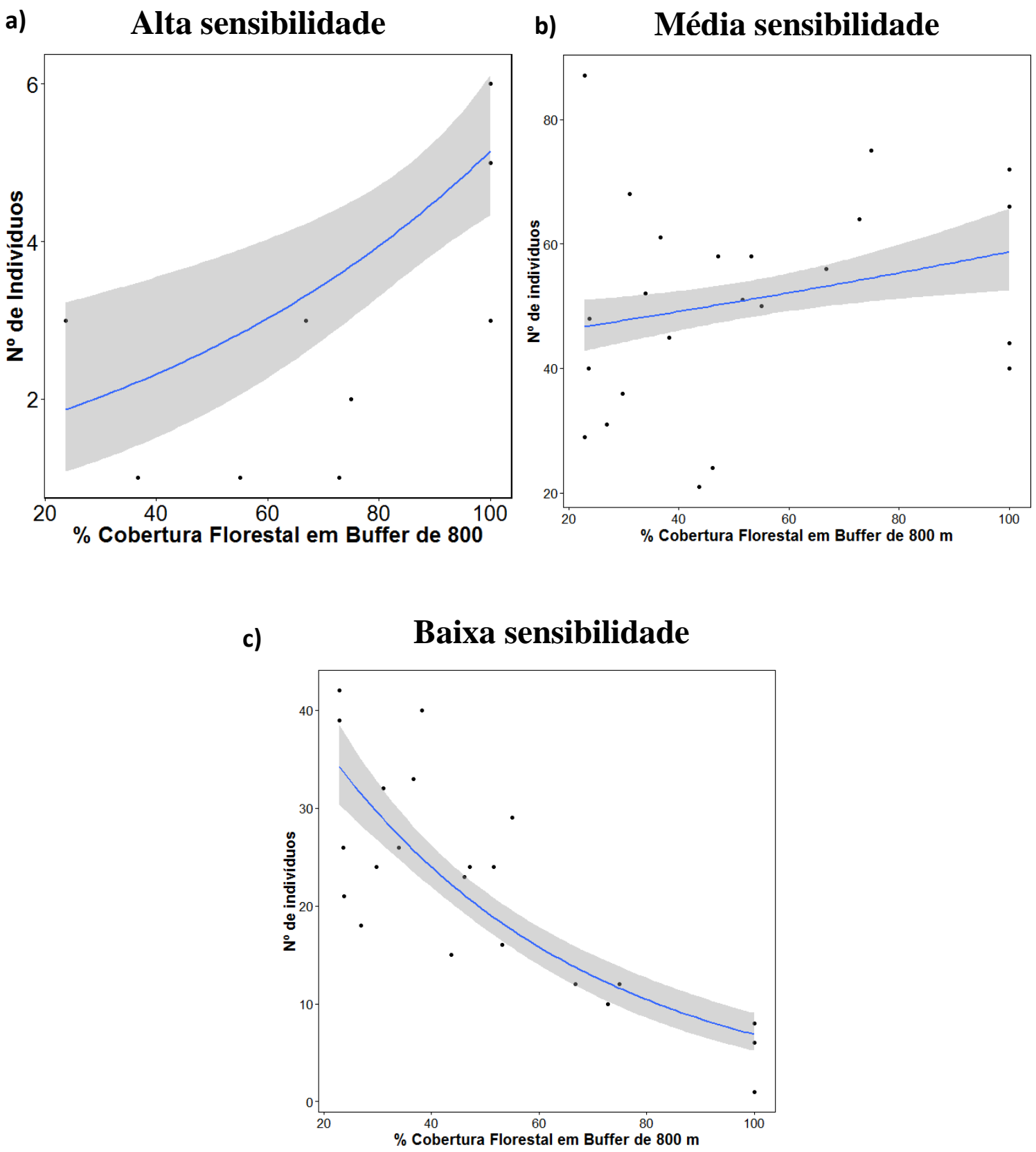

Figura 3. Relação entre número de indivíduos e a porcentagem de cobertura florestal em buffer de $800 \mathrm{~m}$ para as três categorias de sensibilidade à perda de hábitat: a) Alta; b) Média e c) Baixa. 
Já a taxa de recaptura das espécies mais sensíveis não variou em relação à perda de hábitat ( $\mathrm{p}=0,91, \mathrm{z}=0,10$, Fig. 4a), e isso pode ter sido causado pelo fato de que obtivemos poucas recapturas em fragmentos, dificultando uma análise mais confiável. Para as espécies de sensibilidade intermediária e baixa a taxa de recaptura caiu com o aumento da quantidade de mata $(\mathrm{p}<0,001, \mathrm{z}=-3,55$ e $\mathrm{p}=0,05, \mathrm{z}=-1,93$ respectivamente; Fig. 4b, Fig. 4c). Esse padrão foi similar para as demais métricas de quantidade de mata (Anexos VI, VII e VIII), entretanto para espécies de baixa sensibilidade a relação foi significativa apenas para porcentagem de cobertura florestal em buffer de $800 \mathrm{~m}$. 

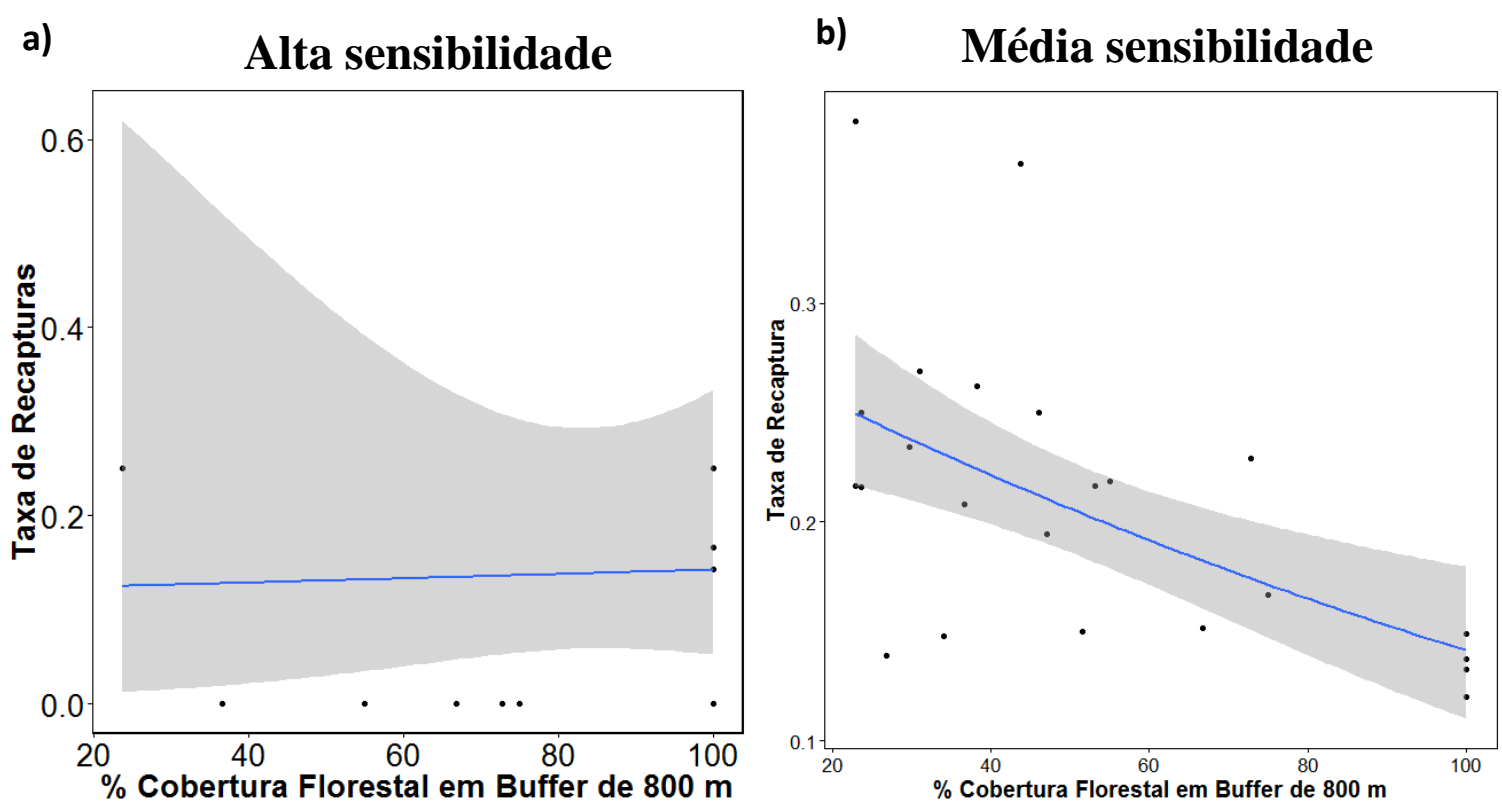

\section{c) Baixa sensibilidade}

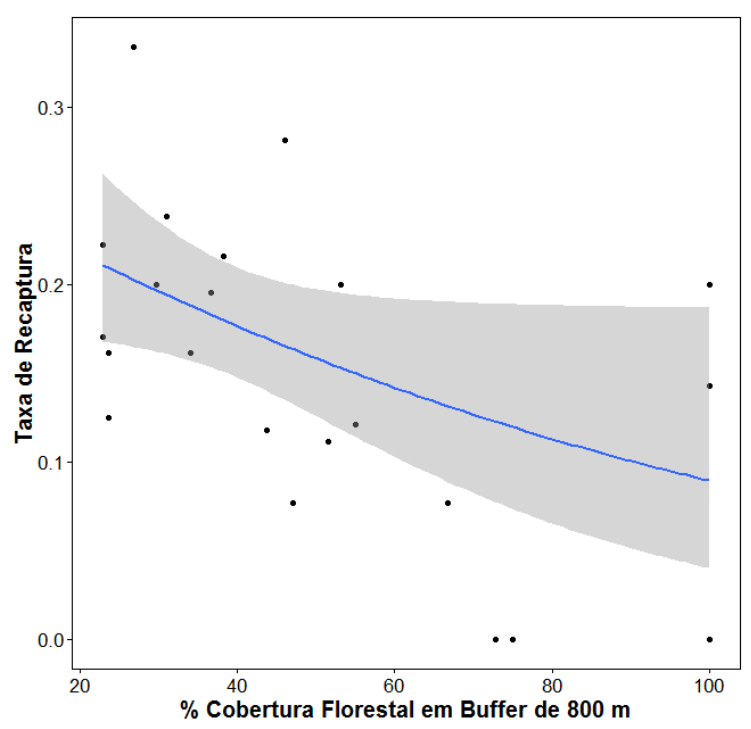

Figura 4. Relação entre a taxa de recaptura e a porcentagem de cobertura florestal em buffer de $800 \mathrm{~m}$ para as três categorias de sensibilidade à perda de hábitat: a) Alta; b) Média e c) Baixa. 


\subsubsection{Guilda trófica}

Quando agrupamos as espécies de acordo com a guilda trófica, observamos que o número de indivíduos das espécies insetívoras cresceu com o aumento da quantidade de mata, enquanto que a taxa de recaptura caiu $(\mathrm{p}<0,001, \mathrm{z}=7,29$ e respectivamente $\mathrm{p}<$ 0,001, $z=-3,36$, Fig. 6). Aves frugívoras responderam da mesma forma ( $p<0,001, z=$ 5,73; $\mathrm{p}<0,001, \mathrm{z}=-5,01$ e Fig. 7 e Fig. 8). Esses padrões de respostas foram observados para todas as métricas de quantidade de hábitat (Anexos IX e X).

a)

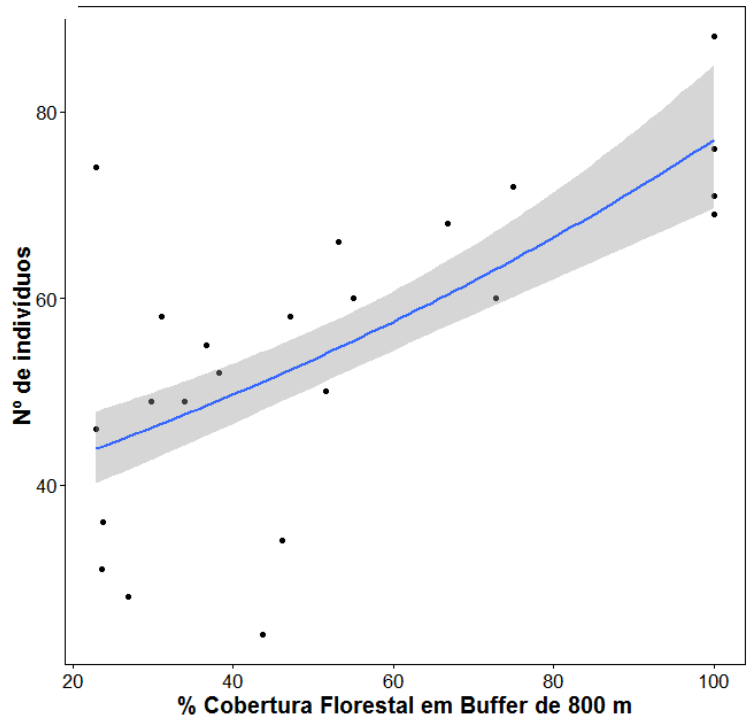

b)

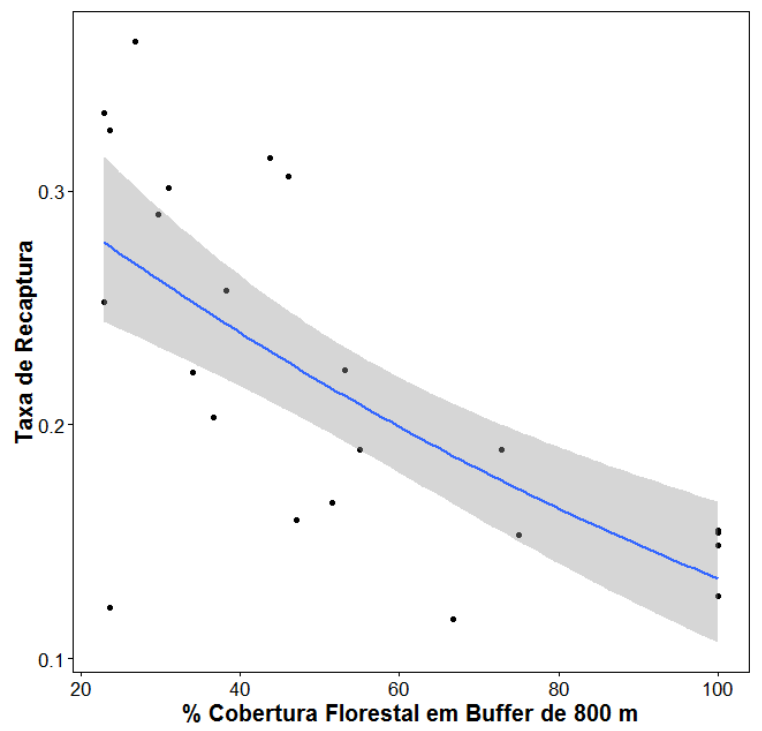

Figura 6. Relação entre a porcentagem de cobertura florestal em buffer de $800 \mathrm{~m}$ e: a) o número de indivíduos capturados e b) a taxa de recaptura, para aves insetívoras. 


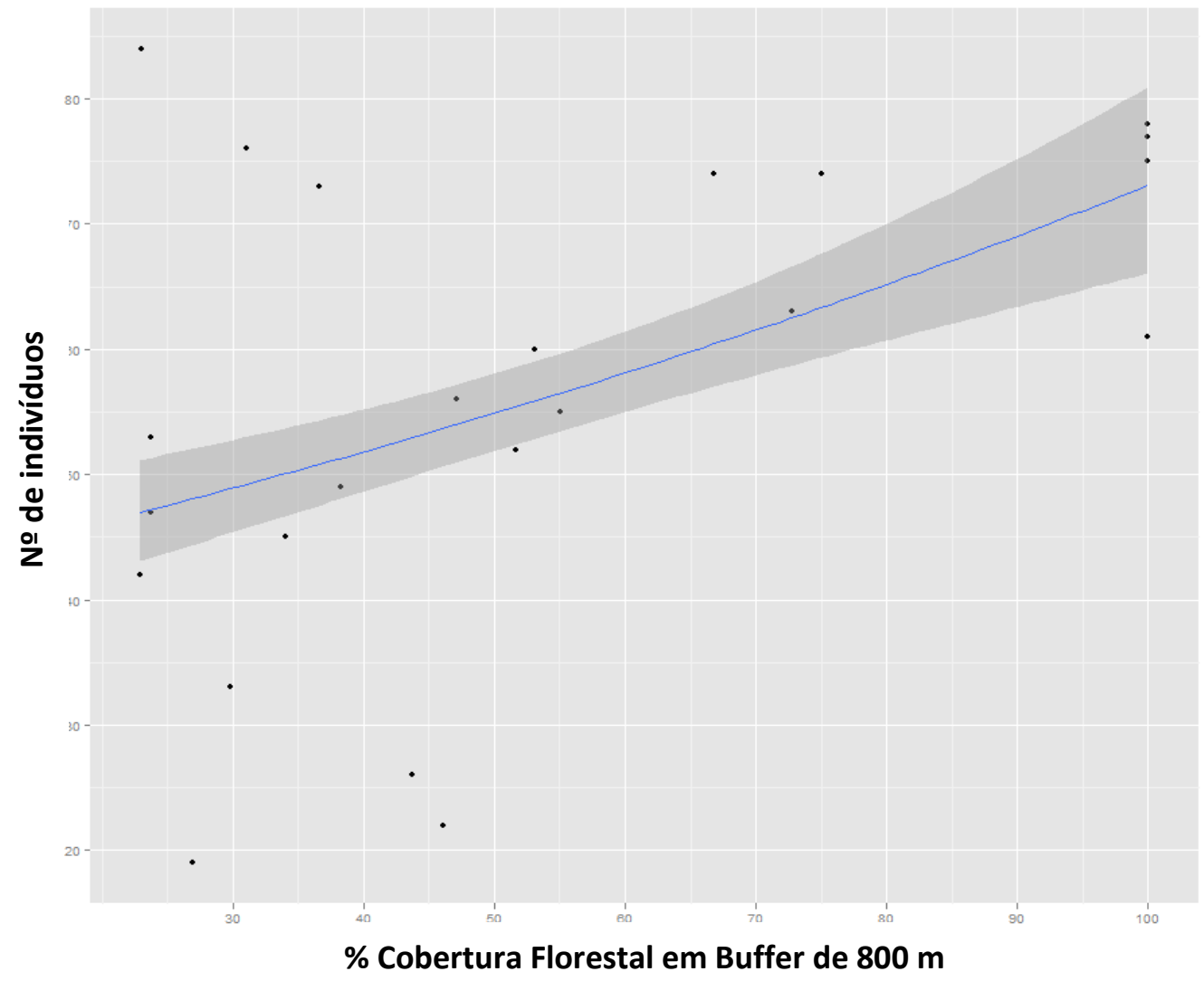

Figura 7. Relação entre a porcentagem de cobertura florestal em buffer de $800 \mathrm{~m}$ e o número de indivíduos capturados, para aves frugívoras. 


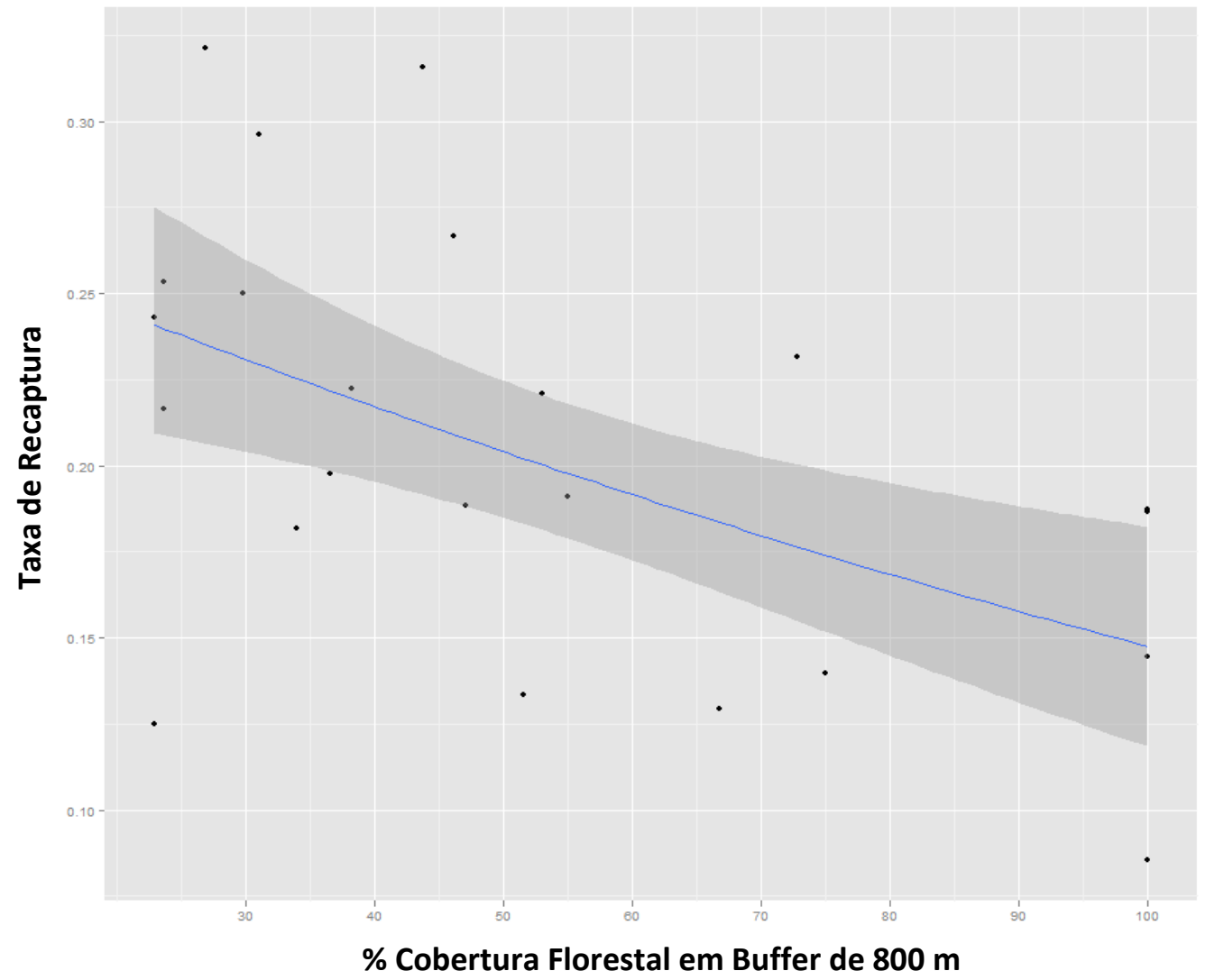

Figura 8. Relação entre a porcentagem de cobertura florestal em buffer de $800 \mathrm{~m}$ e a taxa de recaptura, para aves frugívoras.

\subsubsection{Análise por espécie}

O número de indivíduos capturados de 28 espécies de aves variou em função da quantidade de mata (Anexo II). Dessas, 12 apresentaram redução na abundância com o aumento da quantidade de mata, foram elas Basileuterus leucoblepharus, Conopophaga lineata, Dendrocolaptes platyrostris, Dysithamnus mentalis, Lathrotriccus euleri, Picumnus temminckii, Platycichla flavipes, Syndactyla rufosuperciliata, Tachyphonus coronatus, Thamnophilus caerulescens, Turdus albicollis, Turdus rufiventris. As espécies que apresentaram aumento na taxa de recaptura com o aumento da perda de habitat foram: Basileuterus culicivorus; Chiroxiphia caudata; C. lineata; D. mentalis; P. flavipes. Apenas D. platyrostris apresentou um padrão oposto, diminuindo a taxa de recaptura à medida que a quantidade de mata aumentava. 


\subsection{Qualidade de hábitat}

\subsubsection{Análise da comunidade}

Observamos que para a comunidade de aves o número de indivíduos variou entre as áreas (Fig. 8a; p < 0,001, \% de variância explicada = 0,54), sendo maior em Morro Grande, onde a mata é secundária (Tab. 1). Para esta área, constatamos uma grande variação no número de indivíduos por sítio de coleta, sendo que alguns locais chegaram a ter 200 indivíduos capturados. O número de indivíduos capturados no PEJ também foi significativamente maior que no Sakamoto $(\mathrm{p}<0,001, \mathrm{z}=6,20)$. A paisagem de Morro Grande também apresentou maiores taxas de recaptura, que PEJ e Sakamoto, e não foi encontrada diferença significativa na taxa de recaptura entre estas duas últimas áreas. (Fig. $8 b ; p<0,001, z=0,81)$.

Tabela 1. Soma de indivíduos capturados, número de recapturas e porcentagem de recaptura $\left(\mathrm{n}^{\circ}\right.$ recaptura $/ \mathrm{n}^{\circ}$ recaptura $+\mathrm{n}^{\circ}$ de indivíduos) nas três áreas de floresta contínua.

\begin{tabular}{cccc}
\hline & $\mathbf{N}^{\mathbf{0}}$ de indivíduos & $\mathbf{N}^{\mathbf{0}}$ de Recapturas & $\begin{array}{c}\text { \% de } \\
\text { Recapturas }\end{array}$ \\
\hline Jurupará & 353 & 73 & 17,13 \\
Morro Grande & 397 & 142 & 26,34 \\
Sakamoto & 187 & 49 & 20,76 \\
\hline
\end{tabular}


a)

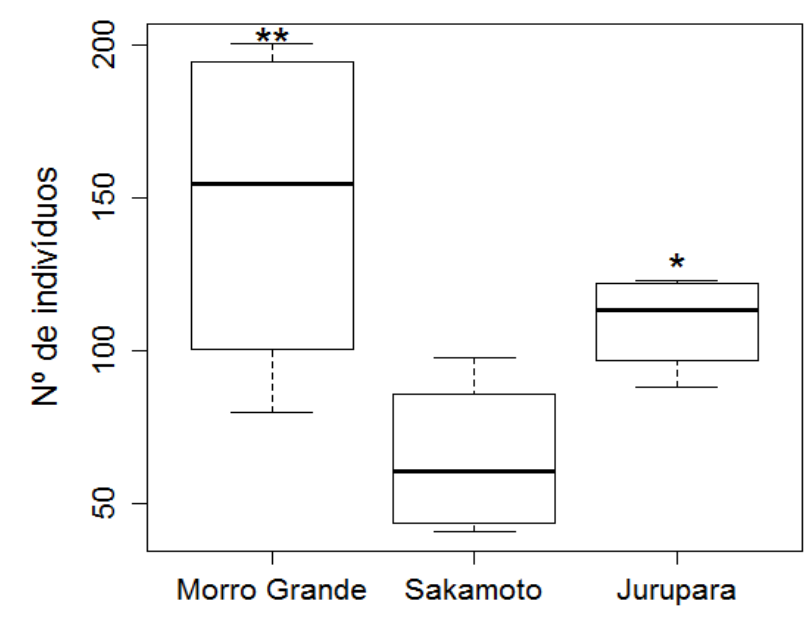

b)

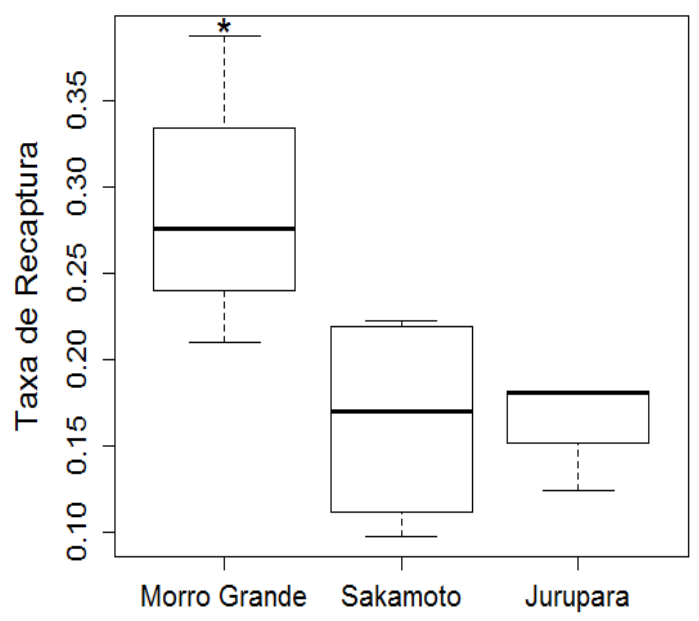

Figura 8 Variação no a) o numero de indivíduos capturados e b) a taxa de recaptura entre as três áreas continuas.

\subsubsection{Análise por espécie}

O número de indivíduos capturados variou em função da qualidade da vegetação para as espécies: C. caudata; Chamaeza campanisona; Harbia rubica; T. albicollis (Fig. 9). Porém, o padrão de resposta foi distinto entre estas espécies. Para as espécies $C$. caudata, C. campanisona e T. albicolis o número de indivíduos capturados foi maior em Morro Grande, área que sofreu corte raso da vegetação e consiste em mata secundária. Já H. rubica teve um número significativamente maior de indivíduos capturados em Jurupará - área que sofreu apenas retirada de palmito. 

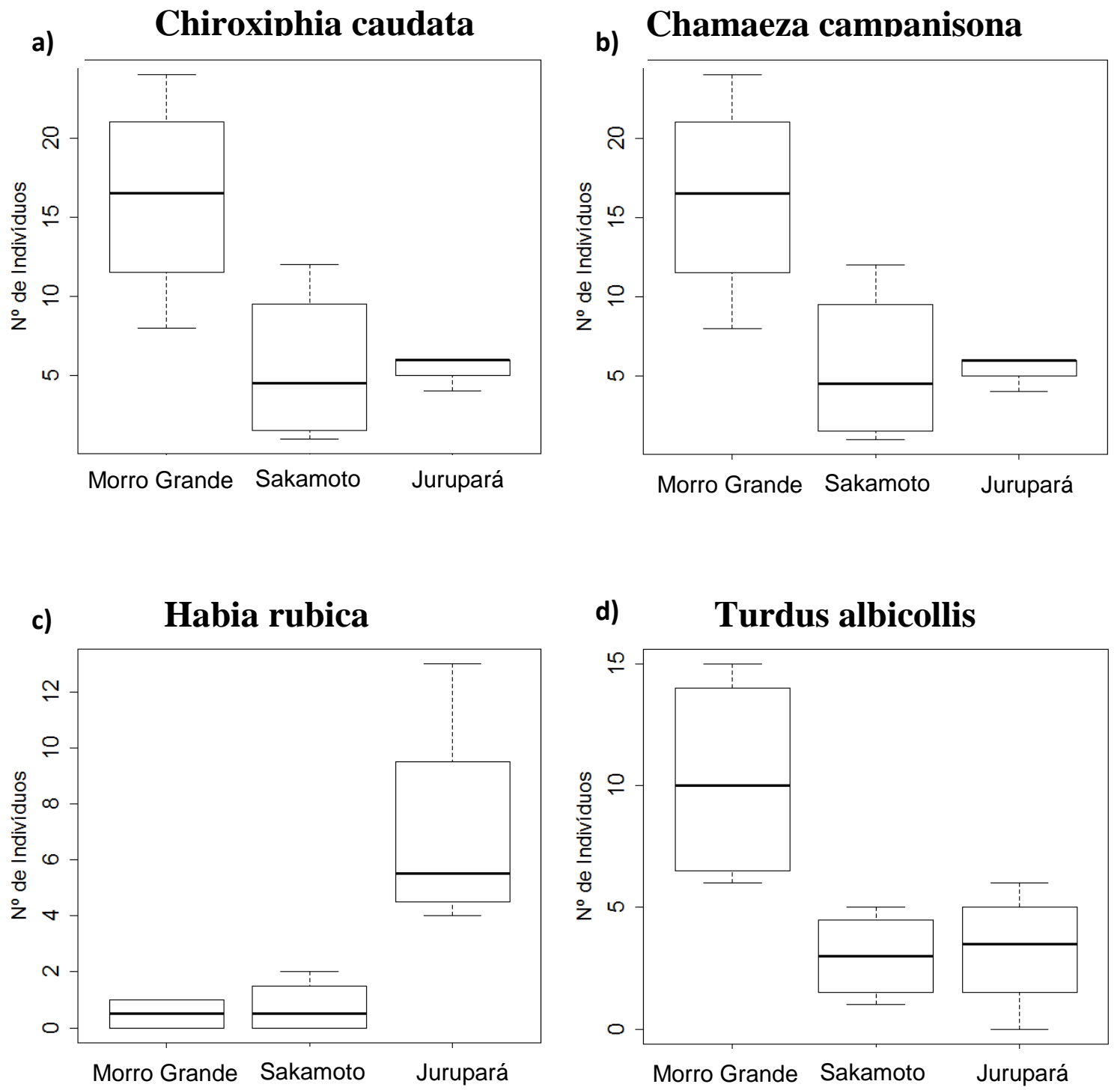

Figura 9. Número de indivíduos das espécies: a) $C$. caudata $(\mathrm{p}=0,01, \mathrm{~F}=6,51)$; b) $C$. campanisona $(\mathrm{p}=0,01, \mathrm{~F}=7,63)$; $)$ H. rubica $(\mathrm{p}=0,006, \mathrm{~F}=9,08) ; \mathrm{d})$ T. albicollis $(\mathrm{p}=0,01$, $\mathrm{F}=6,96$ ); capturados nas áreas de floresta contínua Morro Grande, Sakamoto e Jurupará.

Duas espécies apresentaram variação na intensidade de uso do hábitat: Sclerurus scansor (p $=0,04, \mathrm{~F}=4,69$, Fig.10a) e Trichothraupis menalops $(\mathrm{p}=0,01, \mathrm{~F}=6,76$; Fig. 10b). Podemos observar que indivíduos de ambas espécies possuem uma maior frequência de uso de hábitat na área de Morro Grande - que consiste em uma floresta secundária. 
a)

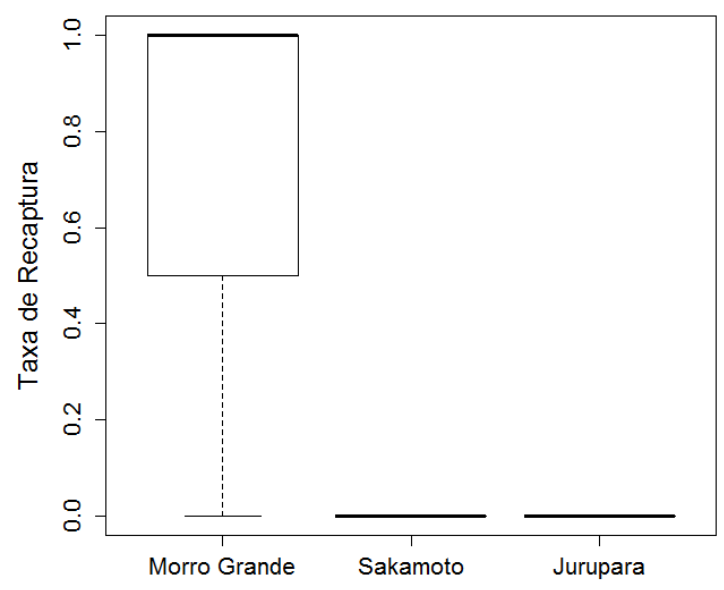

b) Trichothraupis melanops

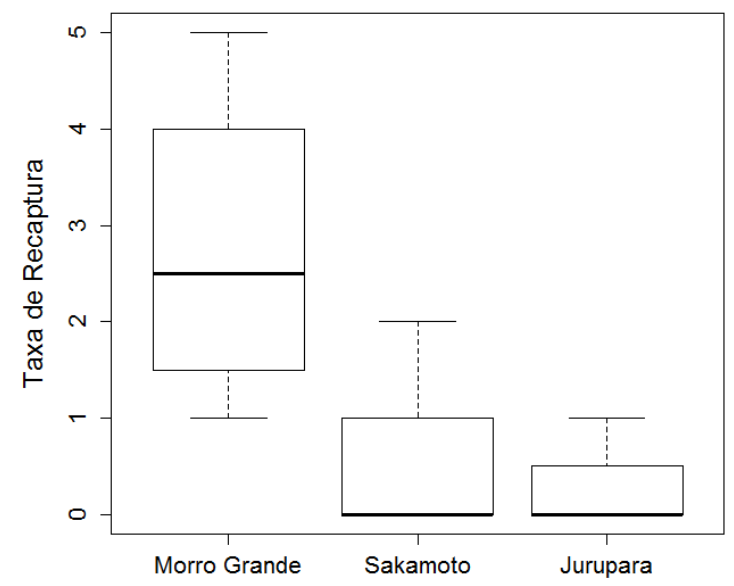

Figura 10. Taxa de recaptura das espécies: a) S. Scansor e b) Trichothraupis melanops capturados nas áreas de floresta contínua Morro Grande, Sakamoto e Jurupará.

\section{Discussão}

No presente estudo observamos que além das alterações na abundância das espécies de aves, a perda de hábitat também altera a intensidade de uso do espaço. Constatamos que, pra a comunidade, à medida que a quantidade de mata dos remanescentes florestais diminui, a frequência de uso do hábitat aumenta e a abundância de indivíduos é reduzida. Em outras palavras, fragmentos pequenos possuem um número menor de indivíduos, mas estes usam a mesma área continuamente. Muitas aves de subosque são predominantemente florestais, mantendo uma relação de interdependência com a floresta. Entretanto, constatamos que até espécies com hábitos generalistas - que teriam uma flexibilidade maior em relação ao hábitat - aumentaram a frequência de uso do espaço com a perda de habitat.

Muitos trabalhos foram feitos com o intuito de entender o movimento e dispersão dos organismos pela matriz disposta entre os fragmentos (Cline \& Hunter Jr 2016; Beyer et al 2016). Barreiras físicas e ecológicas podem afetar o movimento dos organismos (Harris 
$\&$ Reed 2002). Por exemplo, Sieving et al (1996) observou que algumas aves apresentaram certa relutância em atravessar áreas abertas mesmo sendo estimuladas a isso através de playbacks. O mesmo foi observado por Castellón \& Sieving (2006), onde algumas aves foram translocadas para fragmentos florestais e se mediu o tempo que elas demoraram em retornar para suas áreas de origem. Verificou-se que as aves transferidas para fragmentos sem corredores ecológicos demoraram mais para sair, demonstrando certa resistência das mesmas em atravessar a matriz. Bélisle et al (2001) também observou que aves apresentam maior dificuldade em sair das manchas de mata em fragmentos com menor cobertura florestal. Esse padrão de comportamento foi também registrado para outros grupos de animais como borboletas (Schtickzelle et al 2006) e mamíferos (Lidicker Jr 1999). É possível que a maior intensidade no uso do habitat que observamos em nosso estudo ocorra devido um possível aprisionamento de indivíduos dentro das manchas de mata. Porém, também é possível que a variação na intensidade do uso do habitat seja causada por mudanças na área de vida dos indivíduos.

Van Houtan e colaboradores (2007) constataram que espécies de aves amazônicas que se locomoviam muito, diminuíram sua capacidade de dispersão após a fragmentação, tornando-se sedentárias e ficando mais susceptíveis à extinção. Em contrapartida, espécies que já eram sedentárias antes do distúrbio não modificaram sua capacidade de locomoção. Estas aves sedentárias, por já utilizarem áreas menores, estariam mais adaptadas às condições impostas pela fragmentação. Van Houtan e colaboradores (2007) mostram que não foi a mobilidade em si, mas sim a restrição na mobilidade - ocasionada pela barreira da matriz - em resposta à fragmentação que teriam determinado a extinção local dessas aves. No presente trabalho observamos a ausência de espécies sensíveis em fragmentos pequenos, o que vai de encontro com os resultados de Van Houtan et al (2007) já que são espécies com demandas maiores de área e portante, com maior mobilidade.

Quando observamos a resposta geral da comunidade de aves de subosque, constatamos um aumento na frequência de uso do espaço com a diminuição da quantidade de mata. Entretanto, sabemos que as aves presentes nos fragmentos menores são espécies mais generalistas, com média e baixa sensibilidade à perda de hábitat. Ao analisar essas categorias separadamente, constatamos que as espécies de média sensibilidade também são 
afetadas pela perda de hábitat, utilizando os fragmentos menores mais intensamente. A taxa de recaptura de espécies com baixa sensibilidade apresentou relação mais fraca com as métricas da paisagem, demonstrando que não são tão afetadas pela perda de mata. A vulnerabilidade das espécies em paisagens fragmentadas pode ser determinada pela habilidade de usar a matriz como hábitat (Gascon et al 1999). As espécies com baixa sensibilidade não possuem restrições em relação ao uso da matriz, sendo natural que ampliem suas áreas de vida para fora dos fragmentos evitando o aprisionamento.

As espécies com alta sensibilidade apresentaram uma baixa abundância em fragmentos menores. Uma vez que são espécies mais exigentes com as características do ambiente e provavelmente precisam de uma maior quantidade de hábitat para manter suas populações. Alguns estudos apresentaram resultados semelhantes apontando os efeitos negativos da perda de hábitat especificamente para espécies especialistas e sensíveis (Debinski \& Holt 2000; Boulinier et al 2001). Além disso, observamos que espécies com sensibilidade intermediária também responderam negativamente, porém não foram tão fortemente afetadas quanto as espécies mais sensíveis, apresentando uma redução menos acentuada de suas abundâncias com a perda de mata. Espécies generalistas podem utilizar vários tipos de hábitats na paisagem, isso poderia explicar o fato de serem menos afetadas pela fragmentação (Brouat et al 2004). Além disso, a diminuição da abundância de espécies sensíveis pode gerar um alívio na competição e assim favorecer espécies generalistas (Marvier et al 2004).

Já para as espécies com baixa sensibilidade, observamos que a perda de hábitat afetou positivamente suas abundâncias. Estas espécies ocupam prioritariamente ambientes perturbados e estágios iniciais de vegetação (Dent \& Wright 2009) e era esperado que suas abundâncias fossem maiores em paisagens mais fragmentadas. $\mathrm{O}$ padrão diferenciado de resposta entre as espécies sensíveis, generalistas e especialistas em áreas alteradas pode estar relacionado à mudança na composição da comunidade através da substituição de espécies (Summerville \& Crist 2003; Devictor et al 2008a; Banks-Leite et al 2012a; BanksLeite et al 2014). A substituição ocorre quando espécies que ocupam a matriz invadem e colonizam as manchas de mata abandonadas (Brown \& Hutchings 1997) e esse processo pode refletir na variação de abundâncias destas espécies ao longo do tempo ou de um 
gradiente de perda de cobertura florestal - como observado nesse estudo. A mudança na composição da comunidade já foi bem testada (Bierregaard Jr \& Lovejoy 1989; Schmiegelow et al 1997; Boulinier et al 2001), entretanto não há estudos que apresentam a variação da abundância como recortes do processo de substituição de espécies.

A fragmentação - de modo geral - afeta negativamente as grandes árvores e aumenta a abundância de espécies pioneiras, modificando a qualidade do hábitat (BenítezMalvido \& Martínez-Ramos 2003). Assim, a redução da quantidade de mata e da qualidade da mesma andam juntas, podendo esse ser um fator de confusão. Por isso, investigamos como o número de indivíduos e uso do habitat poderia ser influenciado pela qualidade da mata quando se controla o tamanho da área. Entretanto, observamos que a frequência de uso do hábitat pode ser influenciada pela qualidade da vegetação, independente da quantidade de mata ou da presença da matriz, uma vez que registramos um uso mais intenso do espaço na paisagem de Morro Grande - mata secundária. Essa informação pode ajudar a elucidar o mecanismo por trás variação na intensidade do uso de habitat nos fragmentos. Florestas secundárias são estruturalmente simples (Brown \& Lugo 1990), mas possuem alta disponibilidade de frutos (DeWalt et al 2003) e densidade de artrópodes (Adis 1988). Ou seja, para as espécies que são capazes de utilizar áreas perturbadas (e.g. $C$. caudata e T. albicollis), é possível que áreas secundárias providenciem maior quantidade de recursos. Os animais adequam suas áreas de vida para incluir determinados recursos (Mitchell \& Powell 2004). Assim, talvez uma possível causa do uso mais frequente do hábitat na área de Morro Grande, seja a maior concentração de recursos.

Observamos - também - que Morro Grande apresentou uma maior abundância de aves do que Sakamoto, que apenas sofreu corte seletivo. A literatura diverge bastante sobre padrões de abundância em áreas com diferentes estágios sucessionais de vegetação. Alguns estudos atribuem uma maior abundância de animais para matas primárias (MaldonadoCoelho \& Marini 2000; Schieck et al 1995), enquanto que outros encontraram esse padrão para florestas secundárias (Croxall 1976). Thiollay $(1992,1997)$ comparou a composição e estrutura da comunidade de aves antes e depois do corte seletivo. O autor constatou uma queda na riqueza e na abundância após o distúrbio e observou que - mesmo 40 anos após a perturbação - a comunidade de aves não se recuperou. Além disso, registrou também um 
aumento de espécies dominantes. Assim, além da abundância é preciso considerar quais são as espécies que ocorrem no local e que estão sendo beneficiadas. A composição da comunidade de aves em matas secundárias é diferente da que ocorre em matas primárias, sendo que em florestas secundárias há uma concentração maior de espécies generalistas (Drapeau et al 2000). No nosso estudo, análises posteriores constataram que a maioria das espécies registrada em Morro Grande era generalista (41,46\%). A maior concentração de recursos presentes em florestas secundárias (DeWalt et al 2003; Adis 1988) pode ter favorecido uma maior abundância de aves generalistas.

A alteração da intensidade do uso do espaço pode estar relacionada com os mecanismos que levam à perda de espécies nos fragmentos. O confinamento de indivíduos em manchas de mata pode gerar um aumento na taxa de encontros intraespecíficos e consequentemente uma maior frequência de interações agonísticas (Al-Rawi \& Craig 1975). Encontros agressivos entre aves territoriais em fragmentos já foram registrados (Sieving et al 1996). Assim, maior densidade de organismos nos remanescentes florestais pode gerar um aumento nos hormônios relacionados ao estresse (Creel 2001), refletindo em aspectos fisiológicos do indivíduo como a fecundidade, por exemplo (Creel 2001; Mazerolle \& Hobson 2002; Hinam \& St. Clair 2007). A relação entre a perda de hábitat e o aumento de estresse fisiológico foi observada também para outros grupos de animais, como anfíbios (Janin et al 2011) e mamíferos (Martínez-Mota et al 2007). Além de afetar aspectos fisiológicos dos animais, o aumento na intensidade do uso do habitat pode também alterar suas funções ecológicas no ambiente.

As aves de subosque são um grupo de espécies importantes na dispersão de sementes em florestas tropicais (Sekercioglu 2006). O aumento na intensidade do uso do habitat nas manchas de mata pode impedir que as mesmas desenvolvam seu papel de dispersores de sementes entre os fragmentos. Em áreas fragmentadas o tamanho da área de vida das aves é reduzido (Hinam \& St Clair 2008), consequentemente os indivíduos reduziriam sua área potencial de dispersão para a área restrita do fragmento. As bordas dos remanescentes florestais são consideradas barreiras ou filtros para a dispersão de sementes (Fagan et al 1999). Isso levaria à alteração na estrutura da comunidade vegetal. Em uma grande escala espacial, a proporção de sementes depositadas próximo e distante da árvore- 
mãe afeta a habilidade de colonização das plantas (Clark et al 2005), dificulta o fluxo gênico da vegetação, refletindo negativamente na regeneração da floresta (Wunderle Jr 1997). Com distâncias menores de dispersão, as sementes seriam depositadas próxima uma das outras, podendo gerar uma maior competição intraespecífica na comunidade vegetal (Hurtt \& Pacala 1995). Estudos empíricos foram realizados apontando a queda na dispersão de sementes em áreas fragmentadas (Neilan et al 2006).

Estudos sobre uso do espaço hoje praticamente não abordam a intensidade com que o hábitat é utilizado pelos indivíduos. Essa, por sua vez, é uma informação tão importante quanto tamanho da área de vida, que pode nos dizer até mais sobre a relação dos indivíduos com o ambiente. Quantificando apenas tamanho de área de vida, incluímos muitas vezes regiões utilizadas raramente pelos indivíduos. Averiguando a frequência de uso em diferentes locais podemos inferir mais seguramente quais regiões de fato são importantes na área que o indivíduo usa. Estudos que de alguma forma puderam quantificar intensidade de uso utilizaram dados de rádio telemetria (Winker et al 1990; Castellón \& Sieving 2005; Sekercioglu et al 2007; Stouffer 2007), método caro com logística de campo nada simples. Neste trabalho apontamos a utilização de taxa de recaptura como uma alternativa bastante viável neste sentido. Hoje há muitos estudos com grandes esforços amostrais em campo, gerando uma quantidade razoável de dados de recapturas, muitas vezes subutilizados.

\section{Conclusão}

Nesse trabalho, constatamos que além de conduzir a uma perda de espécies e uma queda na abundância, a perda de hábitat também leva o aumento na intensidade do uso do habitat nas manchas de mata. Observamos que não apenas as espécies mais sensíveis são afetadas, mas também espécies de sensibilidade intermediária são influenciadas pela perda de hábitat. Esses resultados reforçam os dados da literatura de que a matriz serve como barreira à dispersão dos animais, entretanto aqui apontamos uma nova abordagem para estudar esses padrões, enfocando na permanência dos indivíduos no fragmento e não na dispersão dos mesmos entre os remanescentes florestais. Além da matriz como barreira à dispersão, a própria qualidade da mata se apresentou como um fator que altera a 
intensidade do uso de habitat, já que verificamos que em mata secundária houve maior taxa de recaptura. Florestas secundárias possuem maiores densidades de insetos e frutos, o que pode ter influenciado na alta frequência de uso do espaço nesse local. $\mathrm{O}$ aumento na intensidade do uso do habitat pode ser um dos mecanismos que explicam a extinção local gerada pela fragmentação e perda de habitat. Sabe-se que a mobilidade está relacionada à persistência dos animais nos fragmentos e também que esses fatores podem refletir em alterações fisiológicas dos indivíduos podendo afetar a fecundidade dos mesmos. Alterações nas interações ecológicas também podem ocorrer. O possível confinamento desses animais nas manchas de mata pode impedir que as mesmas desenvolvam seu papel de dispersores de sementes entre os fragmentos. Por fim, estudos sobre uso do espaço hoje praticamente não abordam a intensidade com que o hábitat é utilizado pelos indivíduos. Essa, por sua vez, é uma informação tão importante quanto tamanho da área de vida, podendo ser estudada através de dados de recaptura dos animais, que são - muitas vezes subutilizados.

\section{Referências bibliográficas}

Adis, J. 1988. On the abundance and density of terrestrial arthropods in Central Amazonian dryland forests. Journal of Tropical Ecology, 4:19-24.

Aizen, M. A. \& Feinsinger, P. 1994. Forest fragmentation, pollination, and plant reproduction in a Chado Dry Forest, Argentina. Ecology, 75:330-351.

Al-Rawi, B. \& Craig, J. V. 1975. Agonistic behavior of caged chickens related to group size and area per bird. Applied Animal Ethology, 2:69-80.

Andreassen, H. P.; Hertzberg, K.; Ims, R. A. 1998. Space-use response to habitat fragmentation and connectivity in the root vole Microtus oeconomus. Ecology79:12231235.

Atwood, T. C. \& Weeks Jr. H. P. 2003. Spatial home-range overlap and temporal interaction in eastern coyotes: the influence of pair types and fragmentation.Canadian Journal of Zoology, 81:1589-1597.

Baguette, M. \& Van Dyck, H. 2007. Landscape connectivity and animal behavior: functional grain as a key determinant for dispersal. Landscape Ecology, 22:1117-1129. 
Banks-Leite, C.; Ewers, R. M.; Kapos, V.; Martensen, A. C.; Metzger, J. P. 2011. Comapring species and measures of landscape structure as indicators of conservation importance. Journal of Applied Ecology, 48:706-714.

Banks-Leite, C.; Ewers, R.; Metzger, J. P. 2012. Unravelling the drivers of community dissimilarity and species extinction in fragmented landscapes. Ecology, 93:2560-2569.

Banks-Leite, C., R. M. Ewers, and J. P. Metzger. 2013. The confounded effects of habitat disturbance at the local, patch and landscape scale on understorey birds of the Atlantic Forest: Implications for the development of landscape-based indicators. Ecological Indicators, 31:82-88.

Banks-Leite, C.; Pardini, R.; Tambosi, L. R.; Pearse W. D.; Bueno, A. A.; Bruscagin, R. T.; Condez, T. H.; Dixo, M.; Igari, A. T.; Martensen, A. C.; Metzger, J. P. 2014. Using ecological thresholds to evaluate the costs and benefits of set-aside in a biodiversity hotspot. Science, 345:1041-1045.

Baur, B. \& Erhardt, A. 1995. Habitat fragmentation and habitat alterations: principal threats to most animal and plant species. Gaia, 4:221-226.

Benítez-Malvido, J. \& Martínez-Ramos, M. Impacts of forest fragmentation on understory plant species richness in Amazonia. Conservation Biology, 17:389-400.

Bélisle, M. 2005. Measuring landscape connectivity: the challenge of behavioral landscape ecology. Ecology, 86:1988-1995.

Beyer, H. L.; Gurarie, E.; Börger, L.; Panzacchi, M.; Basille, M.; Herfindal, I.; Van Moorter, B.; Lele, S. R.; Matthiopoulos, J. 2016. 'You shall not pass!': quantifying barrier permeability and proximity avoindance by animals. Journal of Animal Ecology, 85:43-53.

Bierregaard Jr., R. O. \& Lovejoy, T. E. 1989. Effects of forest fragmentation on Amazonian understory bird communities. Acta amazonica, 19:215-241.

Bierregaard Jr, R. O.; Lovejoy, T. E.; Kapos, V.; Augusto dos Santos, A. Hutchings, R. W. 1992. The biological dynamics of tropical rainforest fragments. BioScience, 42:859866.

Brown, S. \& Lugo, A. E. 1990. Tropical secondary forests. Journal of Tropical Ecology, 6:1-32. 
Blandón, A. C.; Perelman, S. B.; Ramírez, M.; López, A.; Javier, O.; Robbins, C. S. 2016. Temporal bird community dynamics are strongly affected by landscape fragmentation in a Central American tropical forest region. Biodiversity and Conservation, 25:311-330.

Boulinier, T.; Nichols, J. D.; Hines, J. E.; Sauer, J. R.; Flather, C. H.; Pollock, K. H. 2001. Forest fragmentation and bird community dynamics: inference at regional scales. Ecology, 82:1159-1169.

Brouat, C. Chevallier, H.; Meusnier, S.; Noblecourt, T.; Rasplus, J. Y. 2004. Specialization and habitat: spatial and environmental effects on abundance and genetic diversity of forest generalist and specialist Caracus species. Molecular Ecology, 13:18151826.

Boulinier, T.; Nichols, J. D.; Hines J. E.; Sauer, J. R.; Flather, C. H.; Pollock, K. H. 2001. Forest fragmentation and bird community dynamics: inference at regional scales. Ecology, 82:1159-1169.

Castellón, T. D. \& Sieving, K. E. 2005. An experimental test of matrix permeability and corridor use by an endemic understory bird. Conservation Biology, 20:135-145.

Clark, R. G., \& Weatherhead, P. J. 1987. Influence of population size on habitat use by territorial male Red-winged Blackbirds in agricultural landscapes. Auk, 104:311-315.

Cline, B. B. \& Hunter Jr., M. L. 2016. Movement in the matrix: substrates and distance-to-forest edge affect postmetamorphic movements of a forest amphibian. Ecosphere, 7:1-23.

Creel, S. 2001. Social dominance and stress hormones. Trends in Ecology \& Evolution, 16:491-497.

Croxall, J. P. 1976. The composition and behavior of some mixed-species bird flocks in Sarawak. Ibis, 118:333-346.

Debinski, D. M. and Holt, R. D. 2000. A survey and overview of habitat fragmentation experiments. Conservation Biology, 14:342-355.

Dent, D. H. \& Wright, J. S. 2009. The future of tropical species in secondary forests: A quantitative review. Biological Conservation, 142:2833-2843. 
Develey, P. F. 2004. Efeitos da fragmentação e do estado de conservação da floresta na diversidade de aves de Mata Atlântica. PhD thesis. Universidade de São Paulo, São Paulo.

Develey, P. F. \& Metzger, J. P. 2006. Emerging threats to birds in Brazilian Atlantic forests: the roles of forest loss and configuration in a severely fragmented ecosystem. - In: Laurance, W. F. and Peres, C. A. (eds), Emerging threats to tropical forest. University of Chicago Press, pp. 269-290.

Devictor, V.; Julliard, R.; Clavel, J.; Jiguet, F.; Lee, A.; Couvet, D. 2008a. Functional biotic homogenization of bird communities in disturbed landscape. Global Ecology and Biogeography, 17:252-261.

Devictor, V.; Julliard, R.; Jiguet, F. 2008b. Distribution of specialist and generalist species along spatial gradients of habitat disturbance and fragmentation. Oikos, 117:507514.

DeWalt, S. J.; Maliakal, S. K.; Denslow, J. S. 2003. Changes in vegetation structure and compostition along a tropical forest chronosequence: implications for wildlife. Forest Ecology and Management, 182:139-151.

Diffendorfer, J. E.; Gaines, M. S.; Holt, R. D. 1995. The effects of habitat fragmentation on movements of three small mammal species. Ecology, 76:827-839.

Drapeau, P.; Leduc,A.; Giroux, J.F.; Savard, J. P. L.; Bergeron, Y.; Vickery, W. L. 2000. Landscape-scale disturbances and changes in bird communities of boreal mixedwood forests. Ecological Monographs, 70:423-444.

Drickamer, L. C.; Feldhamer, G. A.; Mikesic, D. G.; Holmes, C. M. 1999. Trapresponse heterogeneity of house mice (Mus musculus) in outdoor enclosures. Journal Mammal, 80:410-420.

Estades, C. F.; Escobar, M. A. H.; Tomasevic, J. A.; Vukasovic, M. A.; Páez, M. 2006. Mist-nets versus point counts in the estimation of forest Bird abundances in Southcentral Chile. Ornitologia Neotropical, 17:203-212.

Ewers, R. M. \& Didham, R. H. 2006. Confounding factors in the detection of species responses to habitat fragmentation. Biological Reviews, 81:117-142.

Fahrig, L. 2003. Effects of hábitat fragmentation on biodiversity. Annual Review of Ecology, Evolution and Systematics, 34:487-515. 
Fagan, W. F.; Cantrell, R. S.; Cosner, C. 1999. How habitat edges change species interaction. The American Naturalist, 153:165-182.

Fearnbach, H.; Durban, J.; Parson, K.; Claridge, D. 2012. Photographic markrecapture analysis of local dynamics within an open population of dolphins. Ecology Apply, 22:1689-1700.

Fleming, T. H.; Hooper, E. T.; Wilson, D. E. 1972. Three central American bat communities: structure reproductive cycles, and movement patterns. Ecology, 53:553-569.

Gascon, C.; Lovejoy, T. E.; Bierregaard Jr. R. O.; Malcolm, J. R.; Stouffer, P. C.; Vasconcelos, H. L.; Laurance, W. F.; Zimmerman, B.; Tocher, M.; Borges, S. 1999. Matrix habitat and species richness in tropical forest remnants. Biological Conservation, 91:223229.

Grez, A.; Zaviezo, T.; Tischendorf, L. 2004. A transient, positive effect of habitat fragmentation on insect population densities. Oecologia, 141:444-451.

Harris, M. P.; Freeman, S. N.; Wanless, S.; Morgan, B. J. T.; Wernham, C. V. 1997. Factors influencing the survival of puffins Fratercula arctica at a North Sea colony over 20-year period. Journal of Avian Biology, 28:287-295.

Harris, R. J \& Reed, M. J. 2002. Behavioral barriers to non-migratory movements of birds. Annales Zoologici Fennici, 39:275-290.

Harrison, S. 1999. Local and regional diversity in a patchy landscape: native, alien, and endemic herbs on serpentine. Ecology, 80:70-80.

Hasui, E. 2003. Influência da variação fisionômica da vegetação sobre a composição de aves frugívoras da Mata Atlântica. PhD thesis. Universidade de Campinas, Campinas.

Henle, K.; Davies, K. F.; Kleyer, M.; Margules, C. R.; Settele, J. 2004. Predictors of species sensitivity to fragmentation. Biodiversity and Conservation, 13:207-251.

Hinam, H. L. \& St. Clair, C. C. 2008. High levels of habitat loss and fragmentation limit reproductive success by reducing home range size and provisioning rates of Northern saw-whet owls. Biological Conservation, 141:524-535.

Hurtt, G. C. \& Pacala, S. W. 1995. The consequences of recruitment limitation: reconciling chance, history and competitive diferences between plants. Journal of Theoretical Biology, 176:1-12. 
Ims, R. A.; Rolstad, J.; Wegge, P. 1993. Predicting space use responses to habitat fragmentation: can voles Microtus oeconomus serve as an experimental model system (EMS) for capercaillie grouse Tetrao urogallus in boreal forest? Biological conservation, 63:261-268.

Jenni, L.; Leuenberger, M.; Rampazzi, R. 1996. Capture efficiency of mist nets with comments on their role in the assessment of passerine habitat use. Journal of Field Ornithology, 67:263-274.

Jensen, T. S. 1975. Trappability of various functional groups of the forest rodents Clethrionomys glareoulus and Apodemus flavicollis, and its application in density estimations. Oikos, 26:196-204.

Kruess, A. \& Tscharntke, T. 2000. Species richness and parasitism in a fragmented landscape: experiments and field studies with insects on Vicia sepium. Oecologia, 122:129137.

Köppen, W. 1948. Climatologia. Ed. Fondo Cultura Economica, Mexico City.

Korfanta, N. M.; Newmark, W. D.; Kauffman, M. J. 2012. Long-term demographic consequences of habitat fragmentation to a tropical understory bird community. Ecology, 93:2548-2559.

Lidicker Jr., W. Z. 1999. Responses of mammals to habitat edges: an overview. Landscape Ecology, 14:333-343.

Lourenço, E. C. 2011. Marcação-recaptura de morcegos: Relevância e exemplos de estudos ecológicos. Dissertação de Mestrado. UFRRJ, Rio de Janeiro, 85p.

Lovejoy, T. E.; Rankin, J. M.; Bierregaard Jr, R. O.; Brown Jr, K. S.; Emmons, L. H.; Van der Voort, M. E. 1984. Ecosystem decay of amazon forest remnants. Extinctions. University of Chicago Press, Chicago, 101:295-325.

MacArthur, R. H. \& MacArthur, A. T. 1974. On the use of mist nets for population studies of birds. Proceedings of the National Academy of Sciences, 71:3230-3233.

Maldonado-Coelho, M. \& Marini, M. Â. 2000. Effects of forest fragmentation size and successional stage on mixed-species bird flocks in southeastern Brazil. The Condor, 102:585-594. 
Martínez-Mota, R.; Valdespino, C.; Sánchez-Ramos, M. A.; Serio-Silva, J. C. 2007. Effects of forest fragmentation on the physiological stress response of black howler monkeys. Animal Conservation, 10:374-379.

Martins, J. N.; Printes, R. C.; Schäfer, A. E. 2011. Área de vida e dinâmica do uso do espaço por um grupo de Alouatta guariba clamitans Cabrera, 1940 (Primates, Atelidae), num fragmento de mata com espécies alóctones na Serra Gaúcha. In: Miranda, J. M. D. \& Hirano, Z. M. B. A Primatologia no Brasil, vol 12, Curitiba, UFPR/SPRr.

Marvier, M.; Kareiva, P.; Neubert, M. G. 2004. Habitat destruction, fragmentation, and disturbance promote invasion by habitat generalists in a multispecies metapopulation. Risk Analysis, 24:869-878.

Matthysen, E. 2005. Density-dependent dispersal in birds and mammals. Ecography, 28:403-416.

Mazerolle, D. F. \& Hobson, K. A. 2002. Physiological ramifications of habitat selection in territorial male ovenbirds: consequences of landscape fragmentation. Oecologia, 130:356-363.

McGarial, K. \& Marks, B. J. 1995. Fragstats: Spatial Patterns Analysis Program Quantifying Landscape Structure. Forest Service General Technical Report PNW, Portland, USA.

Metzger, J. P., L. F. Alves, W. Goulart, A. M. G. Teixeira, S. J. C. Simões, and E. L. M. Catharino. 2006. Uma área de relevante interesse biológico, porém pouco conhecida: a Reserva Florestal do Morro Grande. Biota Neotropica, 6:1-33.

Mitchell, M. S \& Powell, R. A. 2004. A mechanistic home range model for optimal use of spatially distributed resources. Ecological Modelling, 177:209-232.

Mysterud, A. \& Ims, R. A. 1998. Functional responses in habitat use: availability influences relative use in trade-off situations. Ecology, 79:1435-1441.

Neilan, W.; Catterall, C. P.; Kanowski, J.; McKenna, S. 2006. Do frugivorous birds assist rainforest succession in weed dominated oldfield regrowth of subtropical Australia? Biological Conservation, 29:393-407.

Ogutu, J. O.; Piepho, H. P.; Dublin, H. T; Reid, R. S.; Bhola, N. 2004. Application of mark-recapture methods to lions: satisfying assumptions by using covariates to explain heterogeneity. Journal of Zoology, 269:161-174. 
Prévot-Julliard, A. C.; Lebreton, J. D.; Pradel, R. 1998. Re-evaluation of adult survival of black-headed gulls (Larus ridibundus) in presence of recapture heterogeneity. Auk, 115:85-95.

Roche, E. A.; Brown, C. R.; Brown, M. B.; Lear, K. M. 2013. Recapture heterogeneity in Cliff Swallows: Increased Exposure to mist nets leads to net avoidance. PlosOne, 8:1-15.

Salewski, V.; Thoma, M.; Schaub, M. 2007. Stopover of migrating birds: simultaneous analysis of different marking methods enhances the power of capturerecapture analysis. Journal of Ornithology, 148:29-37.

Saunders, D. A.; Hobbs, R. J.; Margules, C. R. 1991. Biological consequences of ecosystem fragmentation: A review. Conservation Biology, 5:18-32.

Schmiegelow, F. K.; Machtans, C. S.; Nannon, S. 1997. Are boreal birds resilient to forest fragmentation? An experimental study of short-term community responses. Ecology, 78:1914-1932.

Sekercioglu, C. H. 2006. Increasing awareness of avian ecological function. Trends in Ecology and Evolution, 21:464-471.

Sekercioglu, C. H. 2007. Conservation Ecology: area trumps mobility in fragment bird extinctions. Current Biology, 17:283-286.

Sekercioglu, C. H.; Scott, R. L.; Brenes, F. O.; Ehrlich, P. R.; Gretchen, C. D. 2007. Persistence of forest birds in the Costa Rican agricultural Countryside. Conservation Biology, 21:482-494.

Schieck, J.; Nietfeid, M.; Stelfox, J. B. 1995. Differences in bird species richness and abundance among three successional stages of aspen-dominated boreal forests. Canadian Journal of Zoology, 73:1417-1431.

Schmiegelow, F. K. A.; Machtans, C. S.; Hannon, S. J. 1997. Are boreal birds resilient to forest fragmentation? An experimental study of short-term community responses. Ecology, 78:1914-1932.

Schoener, T. W. \& Schoener, A. 1982. Intraspecific variation in home-range size in some Anolis Lizards. Ecology, 63:809-823.

Schtickzelle, N.; Mennechez, G.; Baguette, M. 2006. Dispersal depression with habitat fragmentation in the bog fritillary butterfly. Ecology, 87:1057-1065. 
Sieving K. E.; Willson, M. F.; De Santo, T. L. 1996. Habitat barriers to movement of understory birds in fragmented south-temperate rainforest. The Auk, 113:944-949.

Stotz, D. et al. 1996. Neotropical birds: ecology and conservation. University of Chicago Press.

Stouffer, P. C. 2007. Density, territory size, and long-term spatial dynamics of a guild of terrestrial insectivorous birds near Manaus, Brazil. Auk, 124:292-306.

Stouffer, P. C. and Bierregaard, R. O. Jr. 1995a. Effects of forest fragmentation on understory hummingbirds in Amazonian Brazil. Conservation Biology, 9:1085-1094.

Stouffer, P. C. and Bierregaard, R. O. Jr. 1995b. Use of Amazonian forest fragments by understory insectivorous birds. Ecology, 76:2429-2445.

Summerville, K. S. \& Crist, T. O. 2003. Determinants of lepidopteran community composition and species diversity in eastern deciduous forest: roles of season, ecoregion, and patch size. Oikos, 100:134-148.

Tavecchia, G.; Pradel, R.; Boy, V.; Johnson, A. R.; Cézilly, F. 2001. Sex- and agerelated variation in survival and cost of first reproduction in greater flamingos. Ecology, 82:165-174.

Thiollay, J. M. 1992. Influence of selective logging on birds species diversity in a Guianian rain forest. Conversation Biology, 6:47-63.

Thiollay, J. M. 1997. Disturbance, selective logging and bird diversity: a Neotropical forest study. Biodiversity and Conservation, 6:1155-1173.

Trajano, 1996. Movements of cave bats in Southeastem Brazil, with emphasis on the population ecology of the common vampire bat, Desmodus rotundus (Chiroptera). Biotropica, 28:121-129.

Van Houtan, K. S.; Pimm, S. L.; Halley, J. M.; Bierregaard Jr.; O.; Lovejoy, T. E. 2007. Dispersal of Amazonian birds in continuous and fragmented forest. Ecology Letters, 10:219-229. 
Veloso, P. H.; Rangel-Filho, A. L. R.; Lima, J. C. A. 1991. Classificação da vegetação brasileira adaptada a um sistema universal. IBGE, Rio de Janeiro.

Verboom, J. Schotman, A.; Opdam, P.; Metz, J. A. J. 1991. European nuthatch metapopulations in a fragmented agricultural landscape. Oikos, 61:146-151.

Villard, M. A.; Martin, P. R.; Drummond, C. G. 1993. Habitat fragmentation and pairing success in the ovenbird (Seiurus aurocapillus). The Auk, 110:759-768.

Whitehead, H. 2001. Direct estimation oh within-group heterogeneity in photoidentification of sperm whales. Marine Mammals Science, 17:718-728.

Winker, K.; Rappole, J. H.; Ramos, M. A. 1990. Population dynamics of the Wood Thrush in Southern Veracruz, Mexico. The Condor, 92:444-460.

Wunderle Jr., J. M. 1997. The role of animal seed dispersal in accelerating native forest regeneration on degraded tropical lands. Forest Ecology and Management, 99:223235. 


\section{Anexos}

Anexo I. Métricas de quantidade de mata dos locais utilizados, juntamente com o total de capturas, de recapturas e porcentagem de recapturas em cada local. Consideramos que as áreas contínuas possuem aproximadamente 10,000 ha, por ser o tamanho da paisagem controle.

\begin{tabular}{|c|c|c|c|c|c|c|}
\hline $\begin{array}{l}\text { Tamanho } \\
\text { Fragmento } \\
\text { (ha) }\end{array}$ & $\begin{array}{c}\% \text { Cobertura } \\
\text { Florestal em } \\
\text { buffer de } 300 \mathrm{~m}\end{array}$ & $\begin{array}{c}\text { \% Cobertura } \\
\text { Florestal em } \\
\text { buffer de } 500 \\
\text { m }\end{array}$ & $\begin{array}{c}\% \text { Cobertura } \\
\text { Florestal em } \\
\text { buffer de } 800 \\
\text { m }\end{array}$ & $\mathbf{N}^{\circ}$ Captura & $\begin{array}{c}\mathbf{N}^{\mathbf{0}} \\
\text { Recaptura }\end{array}$ & $\begin{array}{c}\% \\
\text { Recapturas }\end{array}$ \\
\hline 2,85 & 68,48 & 81,6 & 75,01 & 107 & 18 & 14,4 \\
\hline 3,84 & 19,17 & 23,42 & 26,89 & 37 & 18 & 32,72 \\
\hline 3,89 & 17,79 & 14,03 & 22,93 & 70 & 26 & 27,08 \\
\hline 4,08 & 24,88 & 24,94 & 34,02 & 71 & 17 & 19,31 \\
\hline 4,5 & 29,53 & 28,86 & 23,69 & 63 & 17 & 21,25 \\
\hline 4,93 & 41,69 & 37,46 & 46,13 & 47 & 18 & 27,69 \\
\hline 21,49 & 63,6 & 31,69 & 29,81 & 63 & 23 & 26,74 \\
\hline 23,46 & 52,14 & 44,48 & 38,25 & 82 & 27 & 24,77 \\
\hline 24,21 & 60,42 & 33,95 & 22,97 & 122 & 37 & 23,27 \\
\hline 26,66 & 55,58 & 32,55 & 23,72 & 73 & 20 & 21,50 \\
\hline 27,93 & 65,05 & 50,49 & 55,06 & 86 & 18 & 17,30 \\
\hline 40,11 & 64,15 & 45,36 & 36,62 & 95 & 26 & 21,48 \\
\hline 41,29 & 57,42 & 49,66 & 47,08 & 84 & 18 & 17,64 \\
\hline 61,99 & 74,38 & 50,84 & 31,09 & 100 & 38 & 27,53 \\
\hline 85,3 & 97,81 & 82,52 & 66,8 & 102 & 13 & 11,30 \\
\hline 88,82 & 96,7 & 70,84 & 53,1 & 89 & 21 & 19,09 \\
\hline 96,82 & 40,94 & 47,92 & 43,77 & 34 & 14 & 29,16 \\
\hline 146,23 & 84,41 & 62,54 & 51,63 & 78 & 13 & 14,28 \\
\hline 157,19 & 93,42 & 78,99 & 72,82 & 91 & 22 & 19,46 \\
\hline 10000 & 100 & 100 & 100 & 105 & 13 & 11,01 \\
\hline 10000 & 100 & 100 & 100 & 123 & 22 & 15,17 \\
\hline 10000 & 100 & 100 & 100 & 121 & 22 & 15,38 \\
\hline 10000 & 100 & 100 & 100 & 88 & 16 & 15,38 \\
\hline 10000 & 100 & 100 & 100 & 32 & 4 & 11,11 \\
\hline 10000 & 100 & 100 & 100 & 108 & 24 & 18,18 \\
\hline 10000 & 100 & 100 & 100 & 79 & 17 & 17,70 \\
\hline 10000 & 100 & 100 & 100 & 41 & 4 & 8,88 \\
\hline 10000 & 100 & 100 & 100 & 148 & 40 & 21,27 \\
\hline 10000 & 100 & 100 & 100 & 96 & 27 & 21,95 \\
\hline 10000 & 100 & 100 & 100 & 160 & 62 & 27,92 \\
\hline \multirow[t]{2}{*}{10000} & 100 & 100 & 100 & 62 & 13 & 17,33 \\
\hline & & & Total & 2657 & 668 & 20,09 \\
\hline
\end{tabular}


Anexo II. Relação do número de indivíduos capturados de cada espécie com as métricas de quantidade de hábitat.

\begin{tabular}{|c|c|c|c|c|c|c|c|c|}
\hline \multirow[t]{2}{*}{ Espécie } & \multicolumn{2}{|c|}{$\begin{array}{l}\text { Tamanho do } \\
\text { Fragmento }\end{array}$} & \multicolumn{2}{|c|}{$\begin{array}{c}\% \text { Cobertura } \\
\text { Florestal em } \\
\text { Buffer de } 300 \text { m } \\
\end{array}$} & \multicolumn{2}{|c|}{$\begin{array}{c}\text { \% Cobertura } \\
\text { Florestal em Buffer } \\
\text { de } 500 \mathrm{~m} \\
\end{array}$} & \multicolumn{2}{|c|}{$\begin{array}{c}\text { \% Cobertura } \\
\text { Florestal em Buffer } \\
\text { de } 800 \mathrm{~m} \\
\end{array}$} \\
\hline & $\mathrm{p}$ & $\mathrm{Z}$ & $\mathrm{p}$ & $\mathrm{Z}$ & $\mathrm{p}$ & $\mathrm{Z}$ & $\mathrm{p}$ & $\mathrm{Z}$ \\
\hline $\begin{array}{l}\text { Anabacerthia } \\
\text { amaurotis }\end{array}$ & 0,04 & 2,04 & 0,04 & 2,04 & 0,01 & 2,04 & 0,05 & 2,04 \\
\hline $\begin{array}{c}\text { Automolus } \\
\text { leucophthalmus }\end{array}$ & $<0,001$ & 5,36 & $<0,001$ & 5,36 & $<0,001$ & 5,36 & $<0,001$ & 5,36 \\
\hline $\begin{array}{c}\text { Basileuterus } \\
\text { leucoblepharus }\end{array}$ & 0,07 & $-1,77$ & 0,81 & $-1,77$ & 0,03 & $-1,77$ & 0,009 & $-1,77$ \\
\hline Chiroxiphia caudata & 0,47 & 0,71 & 0,03 & 0,71 & 0,69 & 0,71 & 0,45 & 0,71 \\
\hline Conopophaga lineata & $<0,001$ & $-4,22$ & 0,001 & $-4,22$ & $<0,001$ & $-4,22$ & $<0,001$ & $-4,22$ \\
\hline $\begin{array}{l}\text { Conopophaga } \\
\text { melanops }\end{array}$ & $<0,001$ & 5,02 & $<0,001$ & 5,02 & $<0,001$ & 5,02 & $<0,001$ & 5,02 \\
\hline Dendrocincla turdina & $<0,001$ & 6,59 & $<0,001$ & 6,59 & $<0,001$ & 6,59 & $<0,001$ & 6,59 \\
\hline $\begin{array}{c}\text { Dendrocolaptes } \\
\text { platyrostris }\end{array}$ & 0,01 & $-2,50$ & 0,06 & $-2,50$ & 0,13 & $-2,50$ & 0,25 & $-2,50$ \\
\hline $\begin{array}{l}\text { Dysithamnus } \\
\text { mentalis }\end{array}$ & 0,03 & $-2,14$ & 0,30 & $-2,14$ & 0,04 & $-2,14$ & 0,008 & $-2,14$ \\
\hline Formicarius colma & $<0,001$ & 3,57 & 0,11 & 3,57 & 0,005 & 3,57 & $<0,001$ & 3,57 \\
\hline Geotrygon montana & 0,02 & 2,19 & 0,01 & 2,19 & 0,01 & 2,19 & 0,02 & 2,19 \\
\hline Habia rubica & $<0,001$ & 6,18 & $<0,001$ & 6,18 & $<0,001$ & 6,18 & $<0,001$ & 6,18 \\
\hline Lathrotriccus euleri & 0,004 & $-2,82$ & $<0,001$ & $-2,82$ & 0,008 & $-2,82$ & 0,04 & $-2,82$ \\
\hline Mionectes rufiventris & 0,01 & 2,56 & $<0,001$ & 2,56 & $<0,001$ & 2,56 & $<0,001$ & 2,56 \\
\hline Myiobius barbatus & 0,002 & 3,07 & 0,14 & 3,07 & 0,02 & 3,07 & 0,006 & 3,07 \\
\hline Myrmeciza squamosa & 0,52 & 0,63 & 0,04 & 0,63 & 0,006 & 0,63 & 0,01 & 0,63 \\
\hline $\begin{array}{l}\text { Myrmotherula } \\
\text { gularis }\end{array}$ & $<0,001$ & 6,53 & $<0,001$ & 6,53 & $<0,001$ & 6,53 & $<0,001$ & 6,53 \\
\hline Philydor atricapillus & $<0,001$ & 4,74 & 0,008 & 4,74 & 0,002 & 4,74 & $<0,001$ & 4,74 \\
\hline Picumnus temminckii & 0,18 & $-1,34$ & 0,22 & $-1,34$ & 0,06 & $-1,34$ & 0,04 & $-1,34$ \\
\hline Platycichla flavipes & 0,11 & $-1,57$ & 0,01 & $-1,57$ & 0,19 & $-1,57$ & 0,62 & $-1,57$ \\
\hline Pyriglena leucoptera & 0,17 & 1,34 & $<0,001$ & 1,34 & 0,001 & 1,34 & 0,02 & 1,34 \\
\hline Schiffornis virescens & $<0,001$ & 3,78 & $<0,001$ & 3,76 & $<0,001$ & 3,76 & $<0,001$ & 3,76 \\
\hline $\begin{array}{c}\text { Syndactyla } \\
\text { rufosuperciliata }\end{array}$ & 0,14 & $-1,47$ & 0,10 & $-1,47$ & 0,02 & $-1,47$ & 0,01 & $-1,47$ \\
\hline $\begin{array}{l}\text { Tachyphonus } \\
\text { coronatus }\end{array}$ & 0,34 & $-0,95$ & 0,23 & $-0,95$ & 0,07 & $-0,95$ & 0,04 & $-0,95$ \\
\hline $\begin{array}{l}\text { Thamnophilus } \\
\text { caerulescens }\end{array}$ & 0,14 & $-1,44$ & 0,04 & $-1,44$ & 0,01 & $-1,44$ & 0,02 & $-1,44$ \\
\hline $\begin{array}{l}\text { Trichothraupis } \\
\text { melanops }\end{array}$ & 0,92 & 0,08 & 0,006 & 0,08 & 0,06 & 0,08 & 0,45 & 0,08 \\
\hline Turdus albicollis & 0,04 & $-1,99$ & 0,03 & $-1,99$ & 0,01 & $-1,99$ & 0,005 & $-1,99$ \\
\hline Turdus rufiventris & 0,001 & $-3,18$ & $<0,001$ & $-3,18$ & $<0,001$ & $-3,18$ & $<0,001$ & $-3,18$ \\
\hline
\end{tabular}


Anexo III. Relação entre o número de indivíduos totais capturados em cada área com as métricas de quantidade de mata.
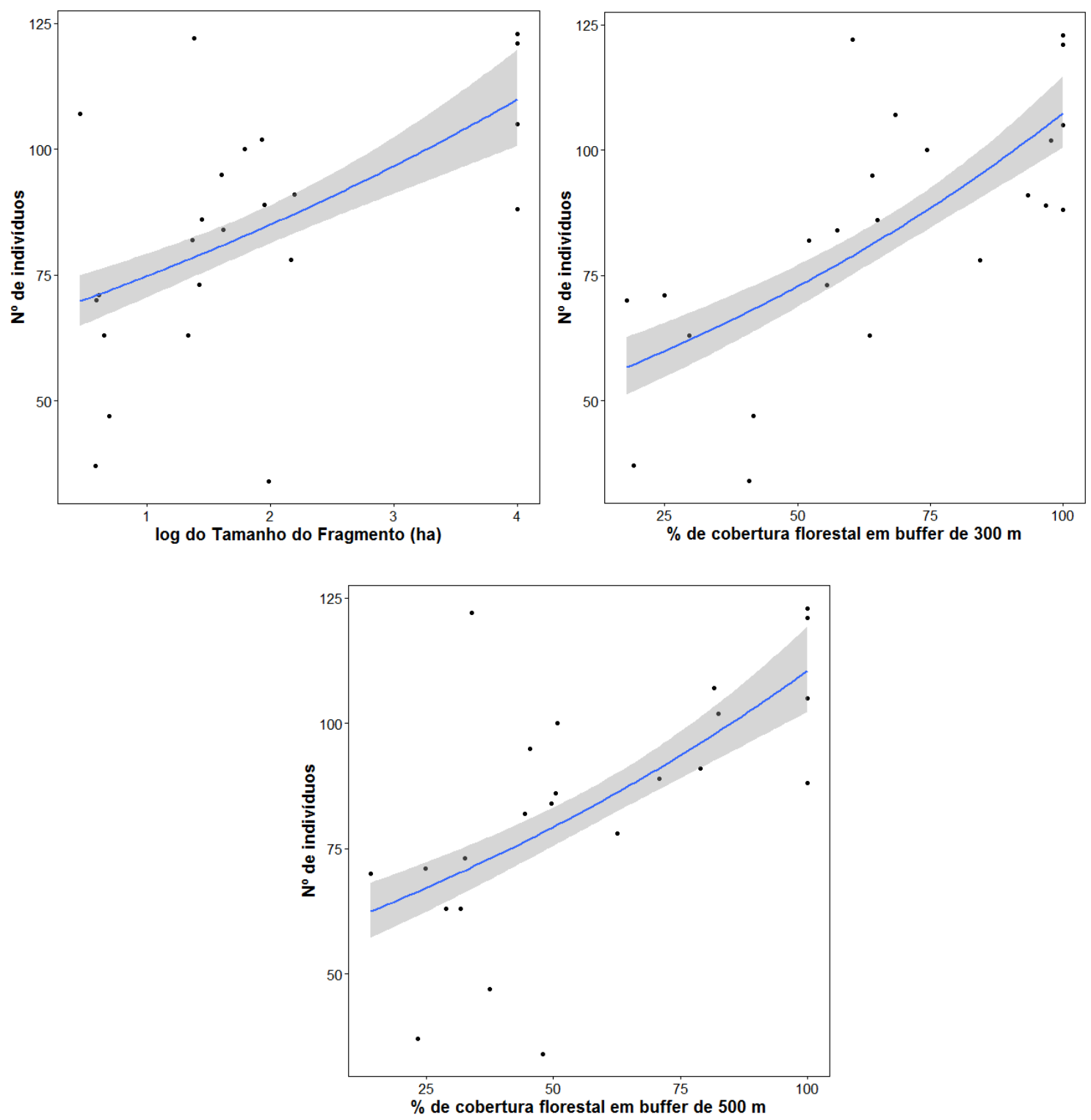
Anexo IV. Relação entre a taxa de recaptura em cada área com as métricas de quantidade de mata.
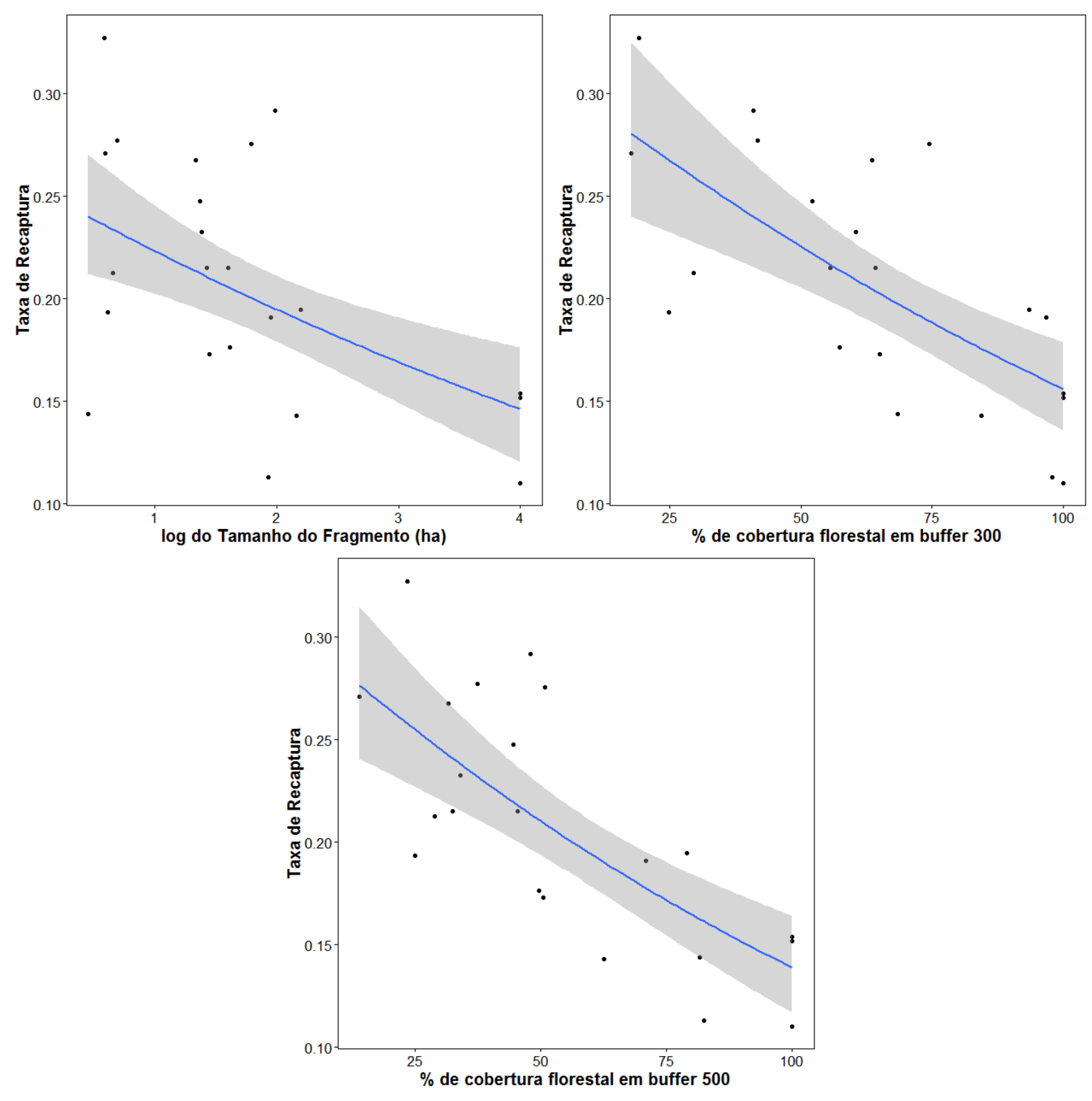
Anexo $V$. Porcentagem de espécies de alta, média e baixa sensibilidade capturadas em cada área, juntamente com as métricas de quantidade de mata.

\begin{tabular}{|c|c|c|c|c|c|c|c|}
\hline $\begin{array}{l}\text { Tamanho } \\
\text { Fragmento } \\
\text { (ha) }\end{array}$ & $\begin{array}{c}\% \\
\text { Cobertura } \\
\text { Florestal } \\
\text { em buffer } \\
\text { de } 300 \mathrm{~m}\end{array}$ & $\begin{array}{c}\% \\
\text { Cobertura } \\
\text { Florestal } \\
\text { em buffer } \\
\text { de } 500 \mathrm{~m}\end{array}$ & $\begin{array}{c}\% \\
\text { Cobertura } \\
\text { Florestal } \\
\text { em buffer } \\
\text { de } 800 \mathrm{~m}\end{array}$ & $\begin{array}{c}\% \text { Alta } \\
\text { sensibilidade }\end{array}$ & $\begin{array}{c}\text { \% Média } \\
\text { sensibilidade }\end{array}$ & $\begin{array}{c}\text { \% Baixa } \\
\text { sensibilidade }\end{array}$ & $\begin{array}{c}\text { Total de } \\
\text { espécies } \\
\text { capturadas }\end{array}$ \\
\hline 2,85 & 68,48 & 81,6 & 75,01 & 9,09 & 68,18 & 22,72 & 22 \\
\hline 3,84 & 19,17 & 23,42 & 26,89 & 0 & 61,53 & 38,46 & 13 \\
\hline 3,89 & 17,79 & 14,03 & 22,93 & 0 & 40,74 & 59,25 & 27 \\
\hline 4,08 & 24,88 & 24,94 & 34,02 & 0 & 59,25 & 40,74 & 27 \\
\hline 4,5 & 29,53 & 28,86 & 23,69 & 0 & 48 & 52 & 25 \\
\hline 4,93 & 41,69 & 37,46 & 46,13 & 0 & 55,55 & 44,44 & 18 \\
\hline 21,49 & 63,6 & 31,69 & 29,81 & 0 & 60 & 40 & 20 \\
\hline 23,46 & 52,14 & 44,48 & 38,25 & 0 & 56 & 44 & 25 \\
\hline 24,21 & 60,42 & 33,95 & 22,97 & 0 & 53,57 & 46,42 & 28 \\
\hline 26,66 & 55,58 & 32,55 & 23,72 & 5,26 & 52,63 & 42,10 & 19 \\
\hline 27,93 & 65,05 & 50,49 & 55,06 & 3,70 & 59,25 & 37,03 & 27 \\
\hline 40,11 & 64,15 & 45,36 & 36,62 & 3,44 & 51,72 & 44,82 & 29 \\
\hline 41,29 & 57,42 & 49,66 & 47,08 & 0 & 64 & 36 & 25 \\
\hline 61,99 & 74,38 & 50,84 & 31,09 & 0 & 60 & 40 & 25 \\
\hline 85,3 & 97,81 & 82,52 & 66,8 & 8,33 & 66,66 & 25 & 24 \\
\hline 88,82 & 96,7 & 70,84 & 53,1 & 0 & 70,58 & 29,41 & 17 \\
\hline 96,82 & 40,94 & 47,92 & 43,77 & 0 & 56,52 & 43,47 & 23 \\
\hline 146,2 & 84,41 & 62,54 & 51,63 & 0 & 63,63 & 36,36 & 22 \\
\hline 157,2 & 93,42 & 78,99 & 72,82 & 5 & 75 & 20 & 20 \\
\hline 10000 & 100 & 100 & 100 & 15,78 & 68,42 & 15,78 & 19 \\
\hline 10000 & 100 & 100 & 100 & 18,75 & 75 & 6,25 & 16 \\
\hline 10000 & 100 & 100 & 100 & 20 & 70 & 10 & 20 \\
\hline 10000 & 100 & 100 & 100 & 15 & 70 & 15 & 20 \\
\hline
\end{tabular}


Anexo VI. Relação da taxa de recaptura e número de indivíduos com as métricas de quantidade de mata para espécies com alta sensibilidade.
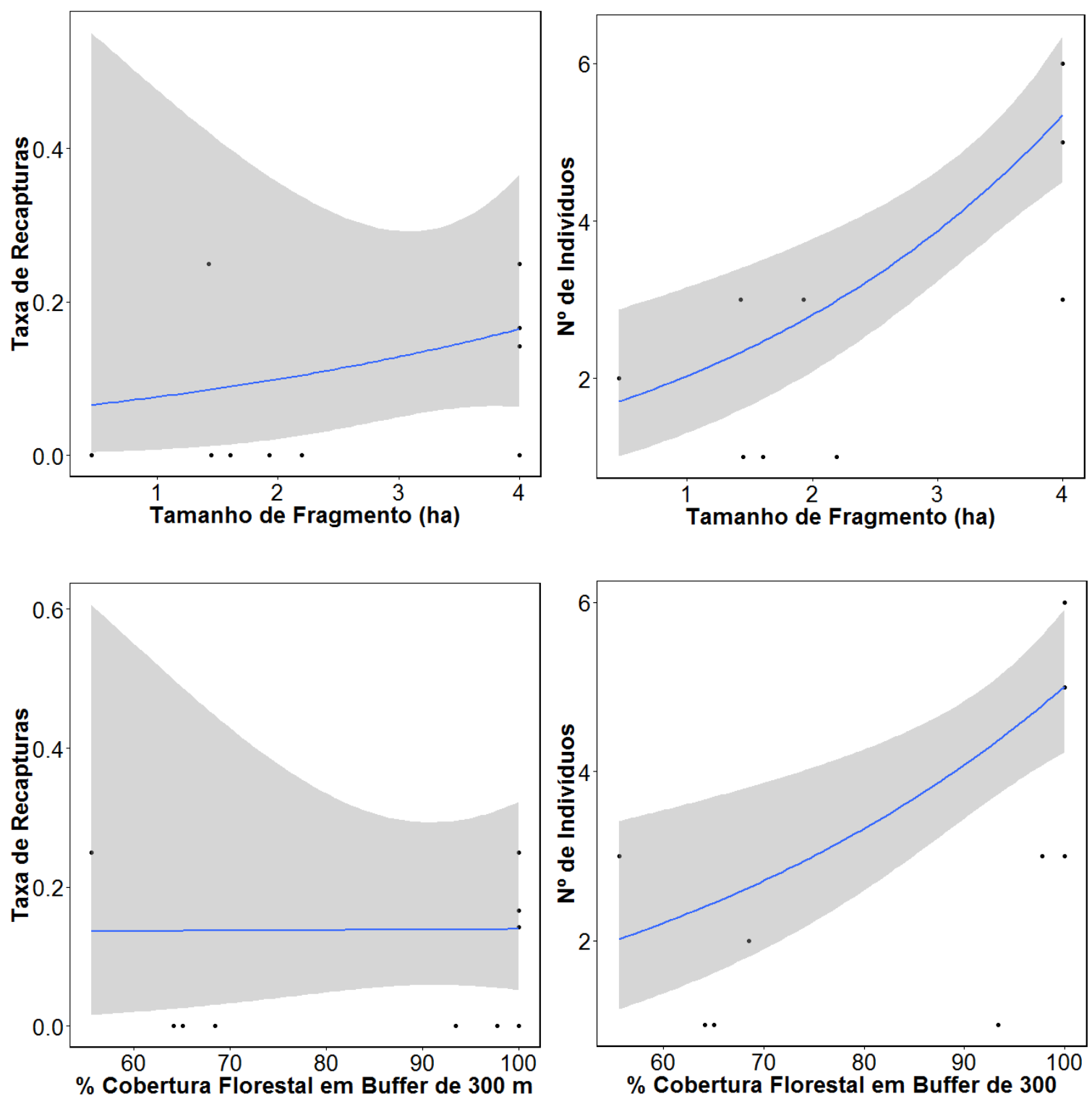

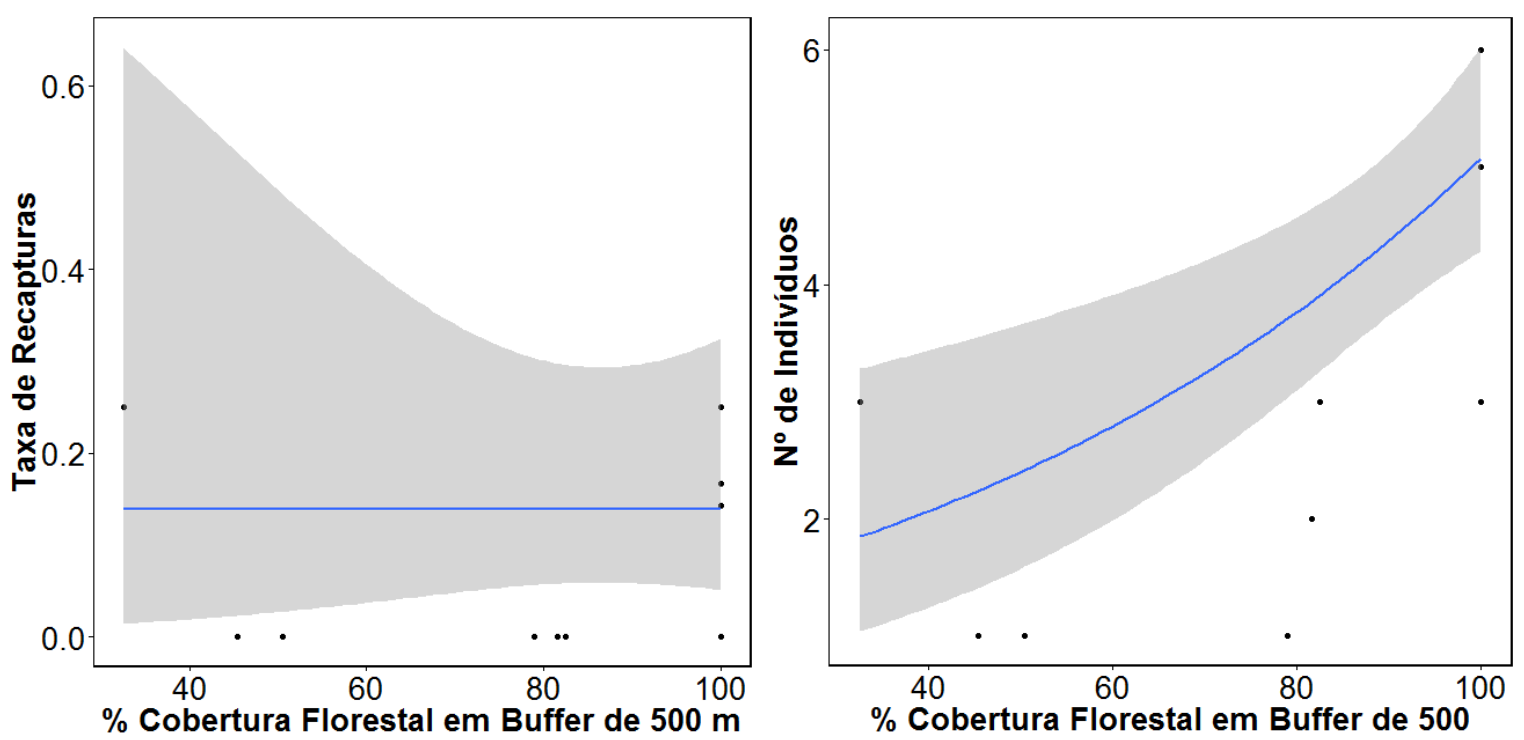
Anexo VII. Relação da taxa de recaptura e número de indivíduos com as métricas de quantidade de mata para espécies com média sensibilidade.
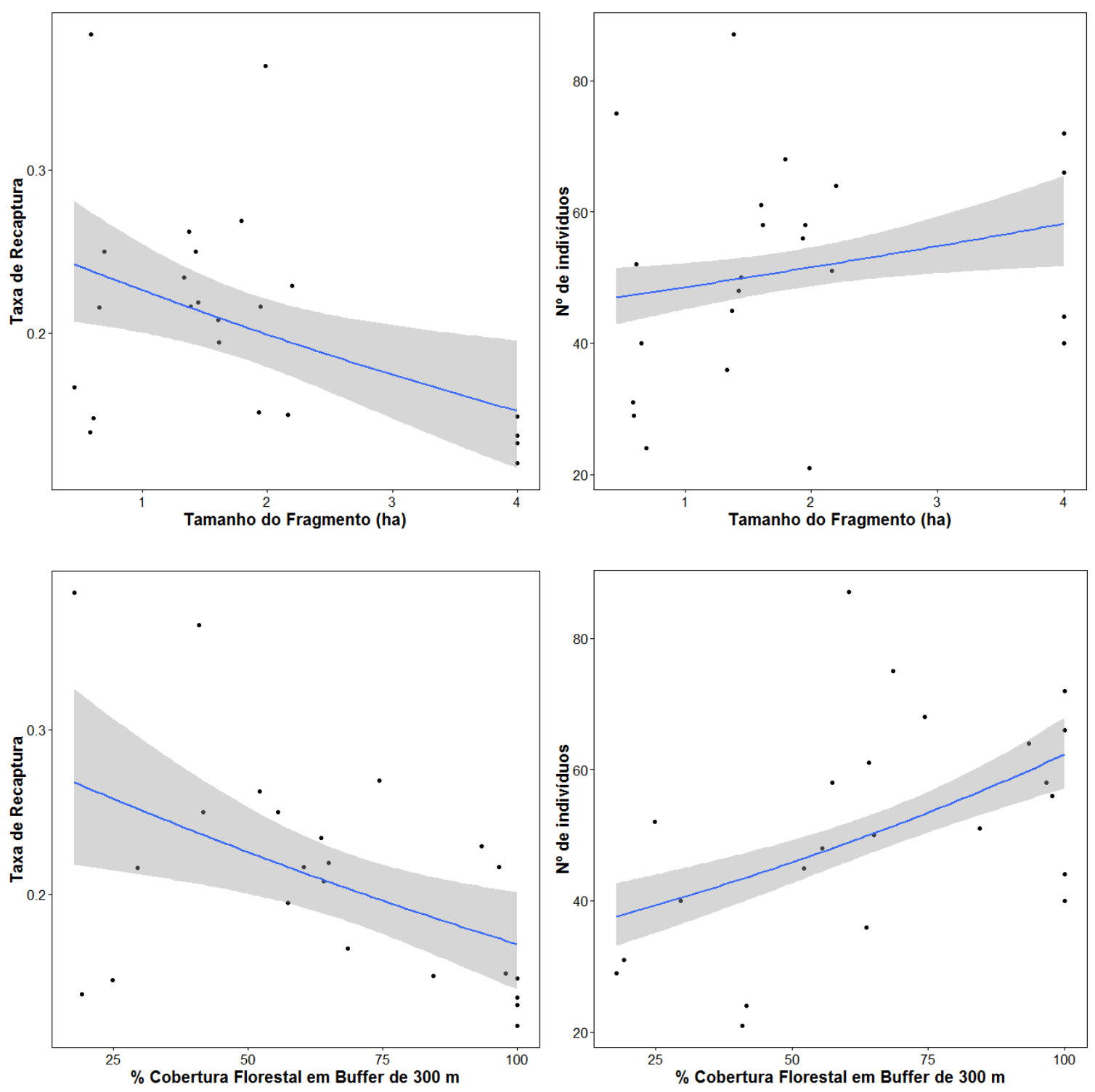

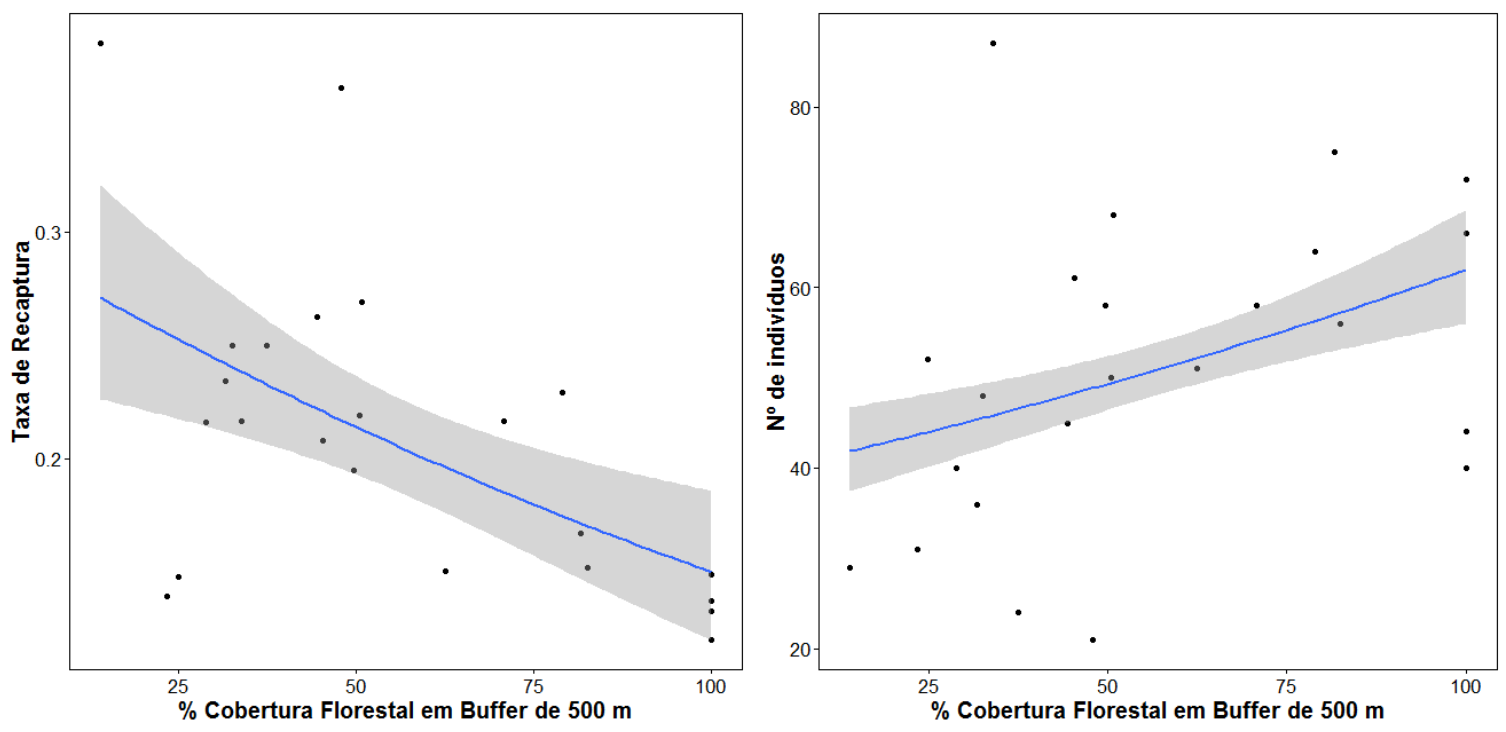
Anexo VIII. Relação da taxa de recaptura e número de indivíduos com as métricas de quantidade de mata para espécies com baixa sensibilidade.
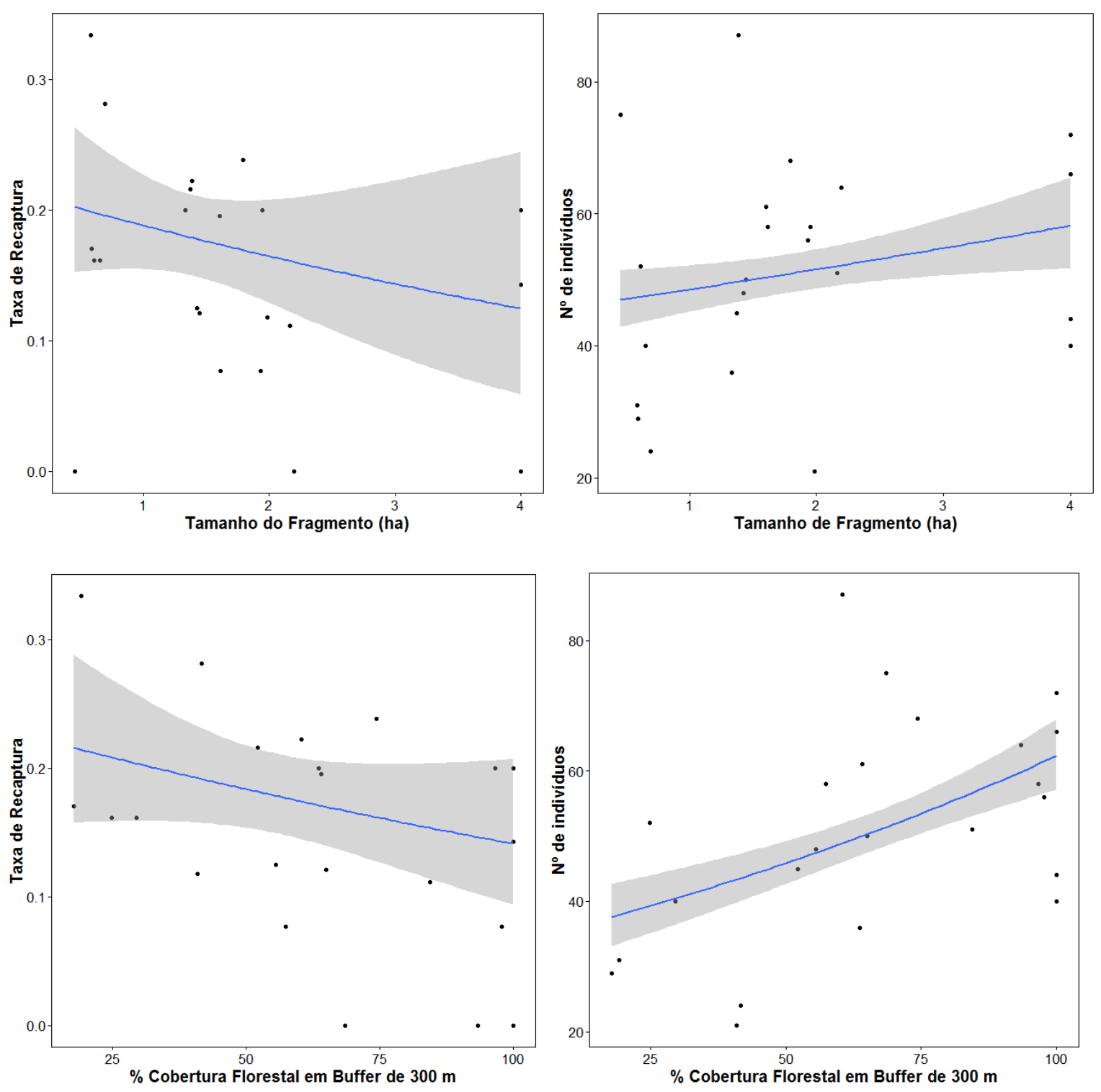

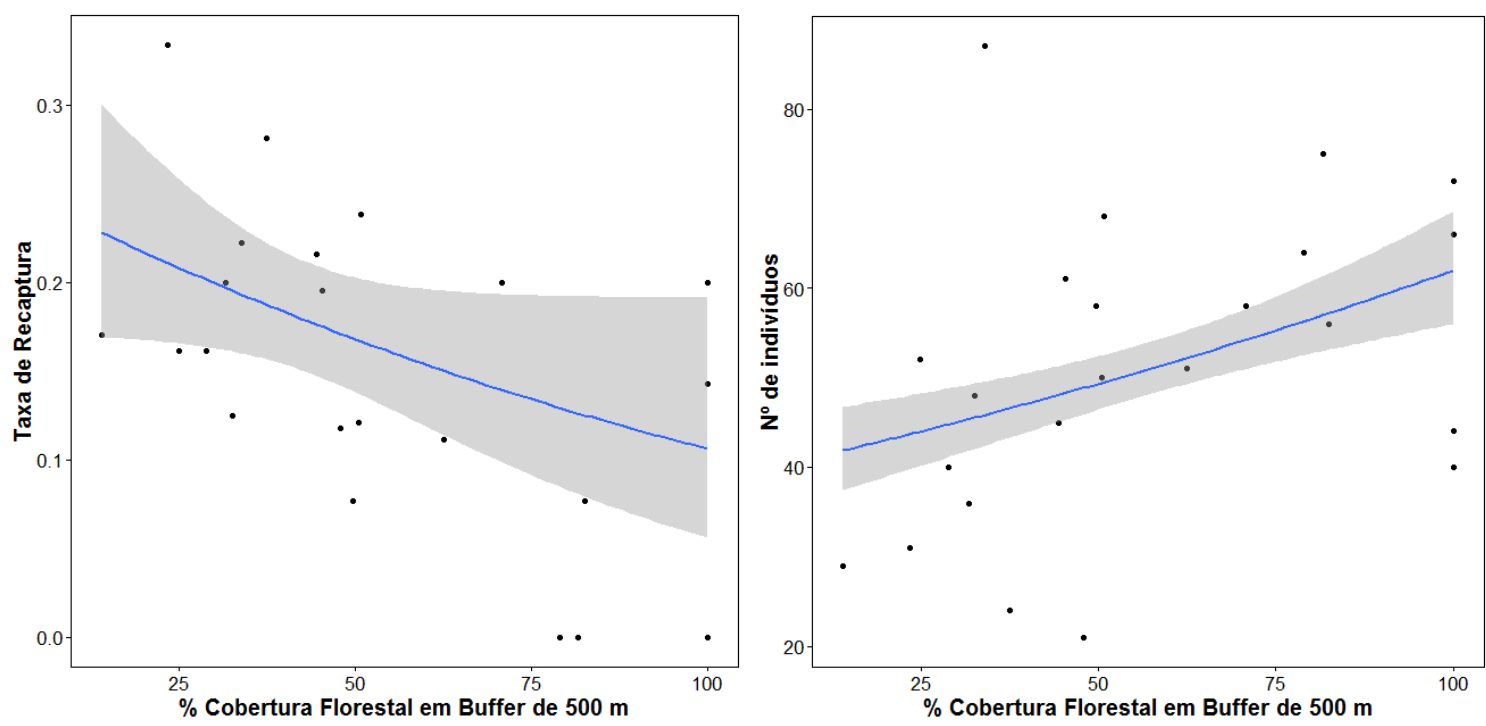
Anexo IX. Relação da taxa de recaptura e número de indivíduos com as métricas de quantidade de mata para espécies insetívoras.
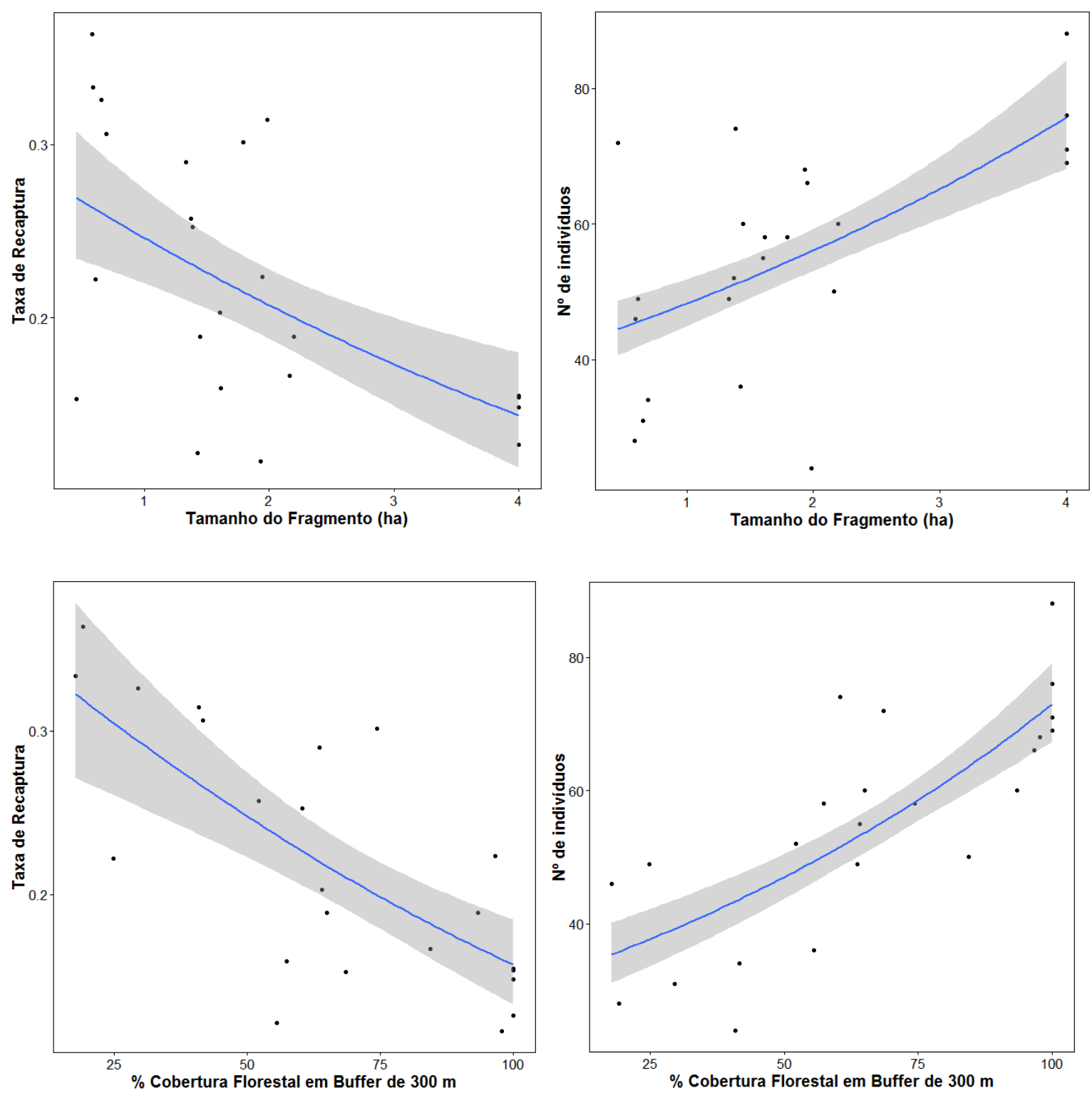

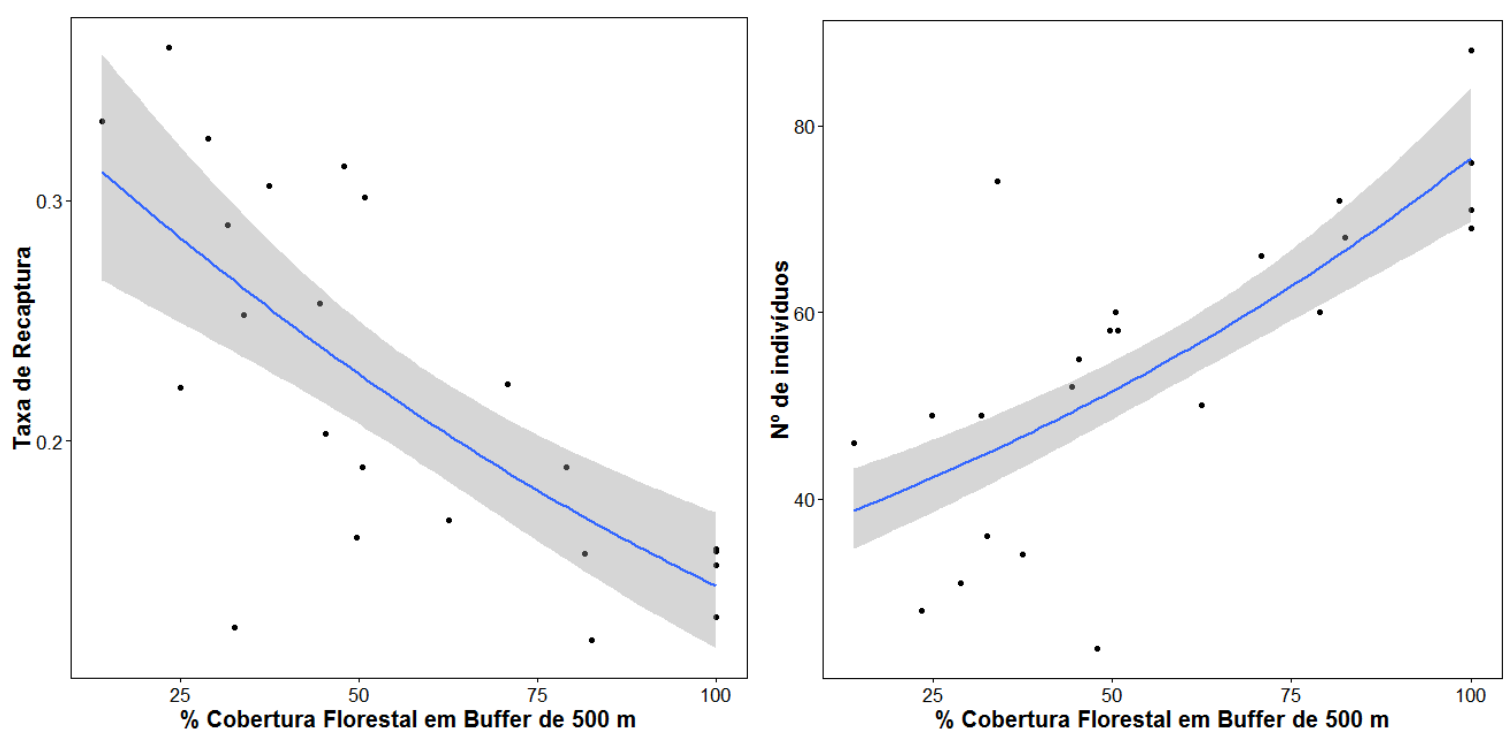
Anexo $X$. Relação da taxa de recaptura e número de indivíduos com as métricas de quantidade de mata para espécies frugívoras.

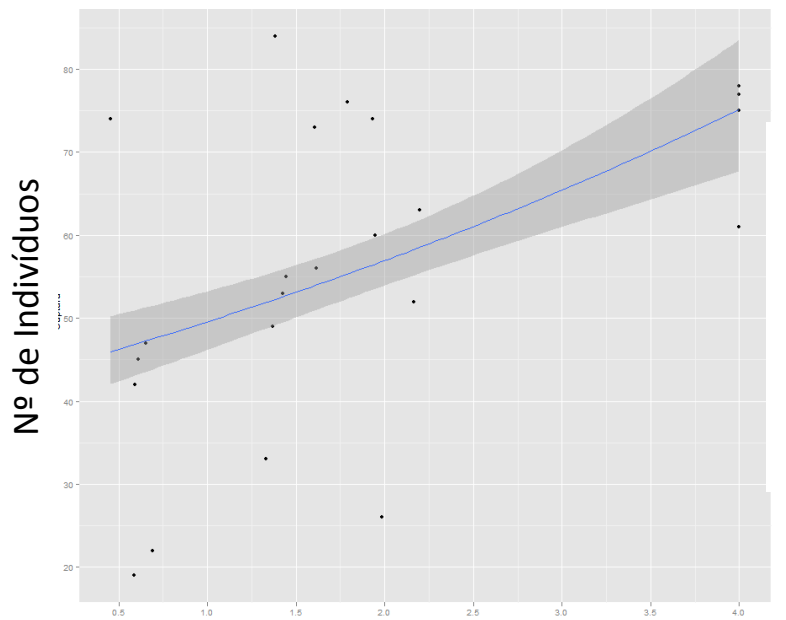

Tamanho de Fragmento

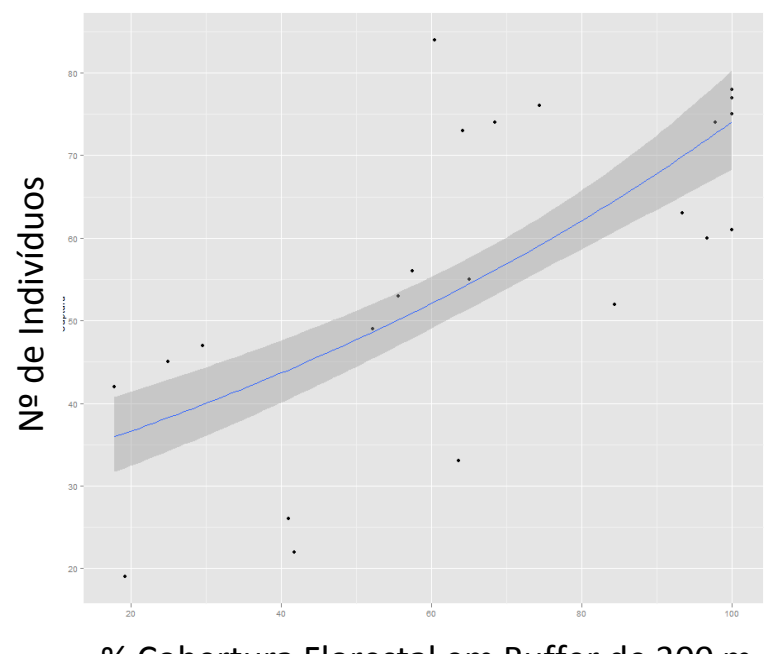

\% Cobertura Florestal em Buffer de 300 m
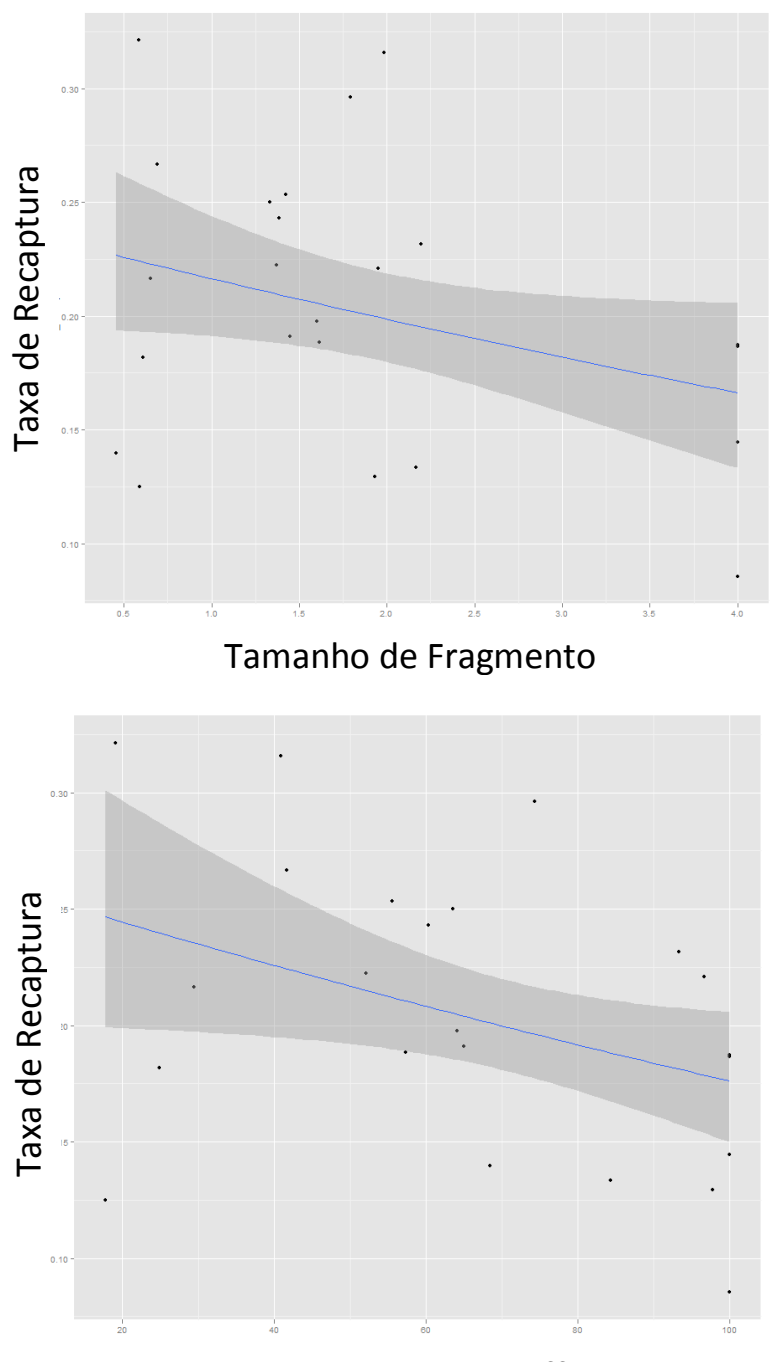

\% Cobertura Florestal em Buffer de 300 m 


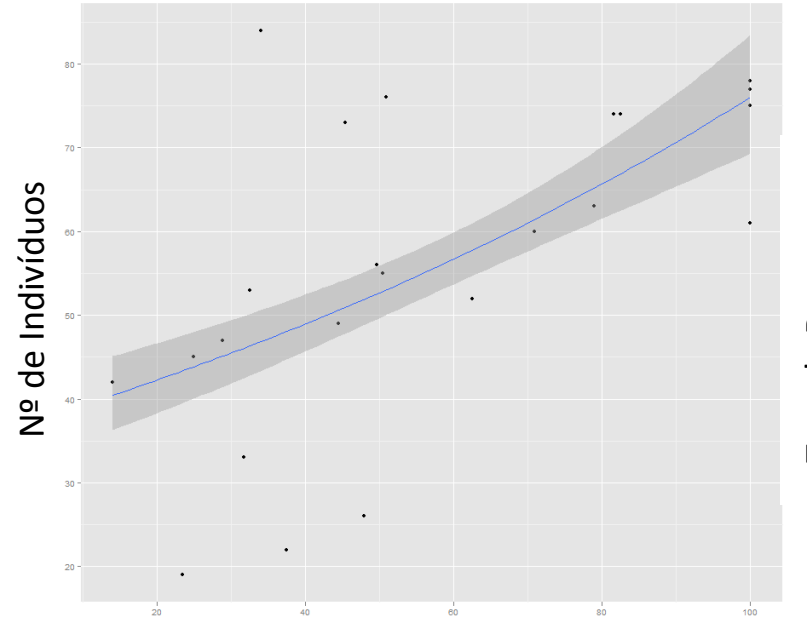

\% Cobertura Florestal em Buffer de 500 m

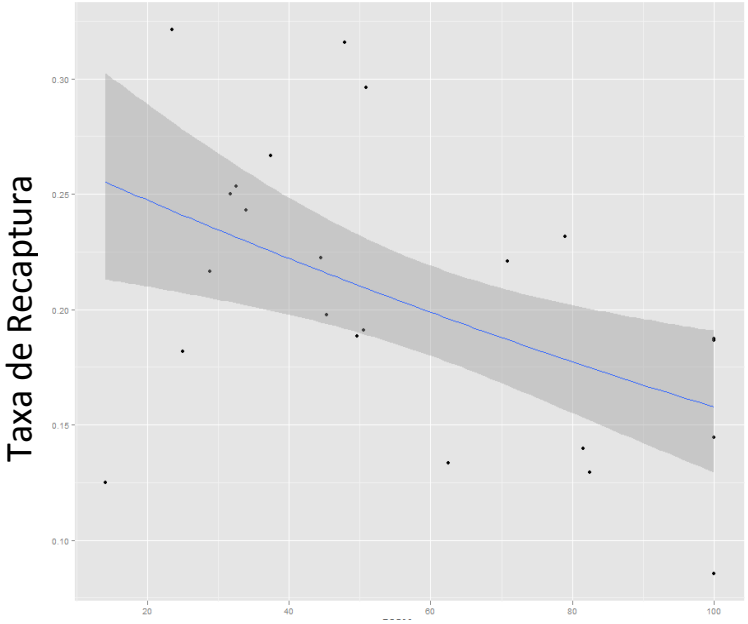

$\%$ Cobertura Florestal em Buffer de 500 m 